\title{
Cost Effectiveness of Screening Individuals With Cystic Fibrosis for Colorectal Cancer
}

\author{
Andrea Gini, ${ }^{1}$ Ann G. Zauber, ${ }^{2}$ Dayna R. Cenin, ${ }^{1,3}$ Amir-Houshang Omidvari, ${ }^{1}$ \\ Sarah E. Hempstead, ${ }^{4}$ Aliza K. Fink, ${ }^{4}$ Albert B. Lowenfels, ${ }^{5,6}$ and Iris Lansdorp-Vogelaar ${ }^{1}$ \\ ${ }^{1}$ Department of Public Health, Erasmus MC, University Medical Center Rotterdam, Rotterdam, The Netherlands; ${ }^{2}$ Department \\ of Epidemiology and Biostatistics, Memorial Sloan Kettering Cancer Center, New York, New York; ${ }^{3}$ Faculty of Health Sciences, \\ Curtin University, Perth, WA, Australia; ${ }^{4}$ Cystic Fibrosis Foundation, Bethesda, Maryland; ${ }^{5}$ Department of Surgery, New York \\ Medical College, Valhalla, New York; ${ }^{6}$ Department of Family Medicine, New York Medical College, Valhalla, New York
}

BACKGROUND \& AIMS: Individuals with cystic fibrosis are at increased risk of colorectal cancer (CRC) compared with the general population, and risk is higher among those who received an organ transplant. We performed a costeffectiveness analysis to determine optimal CRC screening strategies for patients with cystic fibrosis. METHODS: We adjusted the existing Microsimulation Screening Analysis-Colon model to reflect increased CRC risk and lower life expectancy in patients with cystic fibrosis. Modeling was performed separately for individuals who never received an organ transplant and patients who had received an organ transplant. We modeled 76 colonoscopy screening strategies that varied the age range and screening interval. The optimal screening strategy was determined based on a willingness to pay threshold of $\$ 100,000$ per life-year gained. Sensitivity and supplementary analyses were performed, including fecal immunochemical test (FIT) as an alternative test, earlier ages of transplantation, and increased rates of colonoscopy complications, to assess if optimal screening strategies would change. RESULTS: Colonoscopy every 5 years, starting at an age of 40 years, was the optimal colonoscopy strategy for patients with cystic fibrosis who never received an organ transplant; this strategy prevented $79 \%$ of deaths from CRC. Among patients with cystic fibrosis who had received an organ transplant, optimal colonoscopy screening should start at an age of 30 or 35 years, depending on the patient's age at time of transplantation. Annual FIT screening was predicted to be cost-effective for patients with cystic fibrosis. However, the level of accuracy of the FIT in this population is not clear. CONCLUSIONS: Using a Microsimulation Screening Analysis-Colon model, we found screening of patients with cystic fibrosis for CRC to be cost effective. Because of the higher risk of CRC in these patients, screening should start at an earlier age with a shorter screening interval. The findings of this study (especially those on FIT screening) may be limited by restricted evidence available for patients with cystic fibrosis.

Keywords: Colonoscopy Screening; Microsimulation Modeling; Screening Ages; Decision Analysis.

Cystic fibrosis is the most common, life-shortening, autosomal recessive genetic disease among whites. ${ }^{1}$ Approximately 35,000 children and adults have cystic fibrosis in the United States (US), with worldwide prevalence estimated in more than 70,000 individuals. $^{2,3}$
Cystic fibrosis is caused by a mutation in the cystic fibrosis transmembrane conductance regulator gene. Cystic fibrosis impacts multiple organ systems, including respiratory and gastrointestinal. ${ }^{4}$ Because of advances in disease management, detection, and therapy, survival has increased in individuals with cystic fibrosis. The median predicted survival age increased from 33.3 to 41.7 years between 2000 and 2015, and currently more than half of individuals with cystic fibrosis are aged 18 or older. ${ }^{4}$ However, with improved survival, individuals with cystic fibrosis increasingly become at risk for other diseases that typically occur at older ages, especially those involving the gastrointestinal tract. $^{5}$

Gastrointestinal malignancies are an emerging health problem among individuals with cystic fibrosis. Several studies have shown an increased risk of digestive tract cancers and an increased early incidence and progression of adenomatous colorectal polyps to colorectal cancer (CRC). ${ }^{5-8}$ Screening for CRC is a well-established intervention that has been shown to reduce the burden of CRC in the general population. ${ }^{9-17}$ Screening generally starts at the age of 50 for the average risk population, with those at higher risk (such as those with family history of CRC [first-degree relatives] or Lynch syndrome) commencing at an earlier age. ${ }^{18}$ Although those with cystic fibrosis fall into the latter category (their CRC risk exceeds that of those with first-degree relatives), their lower life expectancy may lead to a different trade-off between the benefits and harms of CRC screening. At present, there are no specific recommendations for screening and surveillance for this population.

We performed a decision analysis for the Cystic Fibrosis Foundation and Cystic Fibrosis CRC Screening Task Force, ${ }^{19}$ to explore the benefits, harms, and costs of CRC screening in the CF population and determine the most appropriate CRC screening strategy using a modeling approach.

Abbreviations used in this paper: CRC, colorectal cancer; FIT, fecal immunochemical test; ICER, incremental cost-effectiveness ratio; LYG, life-years gained; MISCAN-Colon, Microsimulation Screening AnalysisColon.

(Q) Most current article

(C) 2018 by the AGA Institute 0016-5085/\$36.00

https://doi.org/10.1053/j.gastro.2017.10.036 


\section{EDITOR'S NOTES \\ BACKGROUND AND CONTEXT}

Individuals with Cystic Fibrosis have shown to be at increased risk of colorectal cancer compared to general population. Although they are at higher risk or colorectal cancer, at present there are no specific screening recommendations for this population.

\section{NEW FINDINGS}

Using a MISCAN-Colon microsimulation model, researchers found that screening in these patients should start at an earlier age with a shorter screening interval compared to the general population.

\section{LIMITATIONS}

The findings of this study (especially those on FIT screening) may be limited by restricted evidence available for patients with cystic fibrosis.

\section{IMPACT}

Colorectal cancer screening in individuals with Cystic Fibrosis is likely cost effective.

\section{Materials and Methods}

We used the Microsimulation Screening Analysis-Colon (MISCAN-Colon) model (Erasmus University Medical Center, Rotterdam, The Netherlands) to assess the effectiveness and costs of screening for CRC among individuals with cystic fibrosis. This model is part of the Cancer Intervention and Surveillance Modeling Network. ${ }^{20}$

\section{MISCAN-Colon Model Description}

MISCAN-Colon is a well-established stochastic microsimulation model for CRC. The structure, underlying assumptions, and calibration of this model have been described in previous studies and in the Supplementary model. ${ }^{20,21}$ Briefly, MISCAN-Colon simulates the life histories of many individuals from birth to death (first without screening and subsequently with screening). As each simulated individual ages, zero, 1, or more than 1 adenomas may develop. These adenomas can progress in size and may develop into (preclinical) cancer. Survival after cancer diagnosis depends on age, stage, and the localization of the cancer at diagnosis. ${ }^{22}$ The introduction of screening may alter the simulated life histories: detection and removal of adenomas may prevent some cancer cases or may detect others at an earlier stage (favorable survival). MISCANColon quantifies the effectiveness and the costs of screening by comparing all the life histories with screening with the corresponding life histories without screening.

MISCAN-Colon was first calibrated to age-, stage-, and localization-specific incidence of CRC as seen in the US general population in the SEER (Surveillance, Epidemiology, and End Results) program before the introduction of the screening (years between 1975 and 1979, Supplementary Figure 1) ${ }^{23}$ and the age-specific prevalence distribution of adenomas seen in autopsy studies (Supplementary Figure 2). ${ }^{24-33}$ Adenoma dwell time and the preclinical duration of CRC were calibrated to the outcomes of the randomized clinical trials evaluating screening using guaiac fecal occult blood tests and sigmoidoscopy. ${ }^{9-12,14,34}$

\section{Adaptions of the MISCAN-Colon Model to the Cystic Fibrosis Population}

The MISCAN-Colon model was adjusted to reflect the increased CRC risk and the elevated all-cause mortality in individuals with cystic fibrosis. Modeling was performed separately for individuals who never received a transplant and those who were post-transplant to account for differences in CRC risk and survival between these 2 groups (non-transplant vs transplant patients). We assumed that the higher CRC risk in both groups was caused by a more frequent adenoma onset (increased probability of adenoma occurrence across all ages), which would result in more CRC.

For individuals with cystic fibrosis who have not had a transplant, the parameters of the model were adjusted to replicate the 7-fold higher CRC risk observed in a 20-year study of 48,188 individuals with cystic fibrosis included in the Cystic Fibrosis Foundation Patient Registry (Figure 1). ${ }^{6}$ Adenoma and advanced adenoma (ie, large adenoma $\geq 10 \mathrm{~mm}$ ) detection rates at 2 different screening rounds were computed and compared with the adenoma detection rates observed in an observational study of people with cystic fibrosis undergoing colonoscopy screening (Supplementary Figure 3). ${ }^{8}$ The model was also adjusted to reflect the overall mortality of individuals with cystic fibrosis in 2015 . $^{4}$

In all analyses for cystic fibrosis transplant patients, we assumed the same adenoma risk as the non-transplant cystic fibrosis population until organ transplantation. We assumed a more frequent onset of adenomas immediately after organ transplant. A 30-fold increase in CRC risk was based on the US cohort study by Maisonneuve et al $^{6}$ (Figure 1). Simulated adenoma and advanced adenoma detection rates were computed and are reported in Supplementary Figure 3. In addition to a higher CRC risk, we also assumed that transplanted individuals with cystic fibrosis had a higher risk of dying of CRC once diagnosed. The increased CRC death-specific risk was modeled as a hazard ratio of 2 based on the excess risk of CRC death using the model provided by Rutter et al. ${ }^{22}$ Life expectancy post transplantation was based on life tables for individuals with cystic fibrosis after lung transplantation. Lung transplants constitute $90 \%$ of transplantations in individuals with cystic fibrosis. ${ }^{4}$ Our model reflected the International Society for Heart and Lung Transplantation's data, which shows that for individuals with cystic fibrosis post-transplant survival is related to time since the transplant and not age. ${ }^{35}$ We simulated this entire population with transplant at the age of 30 years (the median age of transplant) and assessed earlier ages of transplantation in sensitivity analyses to assess if the optimal screening strategies would change.

\section{Screening Strategies Simulated}

For both groups (transplant and non-transplant individuals with cystic fibrosis), a cohort of 10 million individuals, aged 30 years in 2017, was simulated with the adjusted MISCAN-Colon model under 76 different colonoscopy screening strategies (a total of 152 different screening strategies). The strategies differed with respect to (i) screening interval $(3,5$, or 10 years for colonoscopy; (ii) age to start (30, 35, 40, 45, 50 years); and (iii) age to end screening $(55,60,65,70,75$ years). Furthermore, an additional cohort of 10 million individuals aged 30 years in 2017 without cystic fibrosis was simulated to enable a 


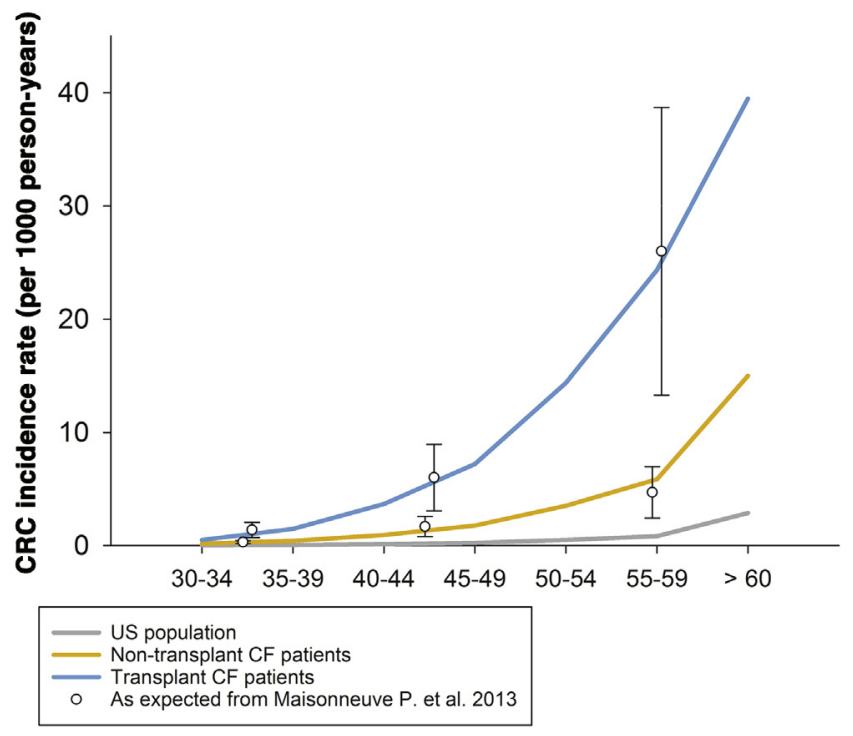

Figure 1. CRC incidence expected in individuals with cystic fibrosis according to Maisonneuve et al. 2013 and CRC incidence simulated in the MISCAN-Colon model without screening in the US general population, non-transplant, and transplant cystic fibrosis patients assuming a higher CRC risk through a more frequent adenoma onset (base case analysis). Note: Bars indicate 95\% confidence intervals; CRC, colorectal cancer; $\mathrm{CF}$, cystic fibrosis.

comparison of outcomes between the cystic fibrosis population and the US general population under the recommended US CRC screening guidelines (colonoscopy starting at age 50, repeated every 10 years).

In addition, given that colonoscopy might be very demanding for individuals with cystic fibrosis, we explored the fecal immunochemical test (FIT) as a possible and hypothetically adequate alternative in this population. As such, we performed a specific supplementary analysis including also annual FIT screening (25 screening strategies).

\section{Screening Assumptions}

Test characteristics and complication rates for each screening test were based on studies in the general population (Supplementary Table 1) (6-40 $^{36}$ because specific information for the cystic fibrosis population is not available.

Modeling FIT screening strategies, we assumed that patients with a positive FIT result were referred for a diagnostic colonoscopy (positive threshold: $100 \mathrm{ng} / \mathrm{ml}$ buffer, equals to $20 \mu \mathrm{g} / \mathrm{g} \mathrm{feces}$. ${ }^{37}$ Individuals with adenomas detected and removed during a screening or diagnostic colonoscopy were assumed to enter colonoscopy surveillance according to the current general population guidelines, ${ }^{18}$ except for colonoscopy screening strategies with 3-year screening interval where a more intensive colonoscopy surveillance interval was introduced in line with the screening interval: every 3 years. We assumed $100 \%$ adherence to screening, diagnostic, and surveillance tests.

Because it is reasonable to consider that the performance of CRC screening in the cystic fibrosis population may be different with regards to colonoscopy complications, adverse events related to a more intensive bowel preparation, and the efficacy of FIT, we address these aspects in specific sensitivity analyses to assess if the optimal screening strategies would be affected.

\section{CRC Screening Costs and Outcomes}

The cost-effectiveness analyses were carried out from a societal perspective. The costs of screening tests were based on the 2014 Medicare payment rates including co-payments (Supplementary Table 2). Complication costs were obtained from a cost analysis study of cases hospitalized after endoscopy in 2007. ${ }^{41}$ Patient time costs were added to both. ${ }^{42}$ The cost of life-years with CRC care were based on the SEER-Medicare linked data analysis and included co-payments and patient time costs. ${ }^{43}$ All costs were adjusted to 2015 using the annual average Consumer Price Indexes provided by the US Bureau of Labor Statistics. ${ }^{44}$ For each simulated cohort, we computed the effectiveness (ie, CRC cases prevented, CRC deaths prevented, and life-years gained [LYG]) and costs of the screening. LYG from screening and costs were discounted by applying the conventional 3\% annual discount rate.

\section{Cost-effectiveness Analyses}

We determined the cost-effectiveness of each screening strategy and compared these results with no screening. Subsequently, we performed an incremental cost-effectiveness analysis to determine the optimal screening strategy. To do this we: (i) ranked all the screening strategies by increasing costs; (ii) excluded all the screening strategies that were more costly and less effective than other strategies ("strongly dominated strategies"); (iii) deleted the screening strategies that were less costly and less effective than another but provided an additional life-year at higher incremental costs ("weakly dominated strategies"); (iv) calculated for all remaining strategies ("efficient strategies," or strategies on the "efficient frontier") the incremental cost-effectiveness ratio (ICER) as the ratio between additional costs and additional clinical benefits (in this case, LYG) of a specific screening strategy compared with the previous less expensive strategy (ie, strategy with costs lower and closest to the strategy of interest); and (v) selected the optimal strategy assuming a willingness to pay threshold of $\$ 100,000$ per LYG.

\section{Sensitivity Analyses}

We conducted multiple sensitivity analyses to test the robustness of the model results under a variety of different assumptions. These assumptions included: (i) lowering colonoscopy test sensitivity for small and medium size adenomas ( 0.65 and 0.80 , respectively); (ii) a more proximal CRC location (50\% of CRC in the right colon); (iii) increasing colonoscopy complication rates 2-fold; (iv) increasing the risk of cardiovascular complications associated with colonoscopy (5- and 10-fold increased risk, including respiratory arrest); (v) lowering FIT specificity (0.90); (vi) a worst case for FIT considering a lower specificity (0.75) and sensitivity (ie, 36\% reduced) in cystic fibrosis population (different FIT performances); (vii) biennial screening intervals for FIT; (viii) lowering adherence to the screening test (80\%); (ix) more intensive colonoscopy surveillance (3 years) for all the screening strategies; and $(\mathrm{x})$ increasing costs because of increased patient time (Supplementary Table 2). 
Additionally, among the non-transplant people with cystic fibrosis, we analyzed the impact of: (i) a higher CRC risk (10-fold increased risk compared with general population); (ii) a higher CRC risk (7-fold) because of a shorter adenoma dwell time (94\% reduced, extremely fast adenoma progression) instead of a more frequent adenoma onset (Supplementary Figure 4); and (iii) a higher all-cause mortality in older ages ( $\geq 45$ years). ${ }^{45}$ For the individuals with cystic fibrosis who have had a transplant, we investigated the impact of: (i) differential age at transplant (20 and 25 years old in 2017); (ii) additional colonoscopy screening strategies (starting at age 32, every 5 years); (iii) increased CRC risk (45-fold increased risk) with a more proximal CRC location (50\% of CRC in the right colon); (iv) utilization of the same age-specific mortality rate observed among non-transplant individuals with cystic fibrosis after age 50 years; and ( $v$ ) higher CRC risk because of a combination of shorter adenoma dwell time (50\% reduced) and higher adenoma onset (16-fold increased risk calibrated to replicate the increased CRC incidence among these individuals; Supplementary Figure 4).

\section{Results}

Without screening, the model predicted 19.1 CRC deaths per 1000 30-year-old individuals with cystic fibrosis who have not had a transplant. Among those who had a transplant, 22.3 CRC deaths per 1000 individuals were predicted to die from CRC (Table 1). The recommended US CRC screening strategy was estimated to prevent more than $73 \%$ of the CRC deaths among the US general population, $66 \%$ of CRC deaths among individuals with cystic fibrosis, and $39 \%$ of individuals with cystic fibrosis post-transplant. However, only $22 \%$ of individuals who received a transplant and $36 \%$ of those who did not were predicted to survive in the model until age 50 , thereby meeting the age requirement to participate in this screening strategy (Figure 2).
The costs and benefits of all simulated screening strategies for transplant and non-transplant individuals with cystic fibrosis were investigated (Supplementary Tables 3-6) and strategy-specific efficient frontiers are reported in Figure 3. Among the efficient colonoscopy screening strategies, LYG from screening varied from 29 to 57 (per 1000 individuals 30 years of age) for non-transplant and from 28 to 64 for transplant cystic fibrosis patients. Higher benefits were associated with colonoscopy screening every 3 years from age 30 to 75 , while the lower values for LYG for individuals with cystic fibrosis with and without organ transplant were observed, respectively, screening with once-lifetime colonoscopy at age 50 and 10-yearly colonoscopy from age 45 to 55 .

For non-transplant individuals with cystic fibrosis, when only colonoscopy was considered as a screening test, the optimal colonoscopy strategy was 1 screen every 5 years from 40 to 75 years of age with an ICER of \$84,000 per LYG (Table 2). This strategy predicted 25 CRC cases and 4 CRC deaths to occur, equating to a reduction of $52 \%$ in CRC incidence and 79\% for CRC mortality (Table 2). Among transplanted cystic fibrosis patients, colonoscopy screening repeated every 3 years between ages 35 and 55 was optimal, preventing $82 \%$ of CRC mortality (ICER of $\$ 71,000$ per LYG) compared with no screening (Table 3).

When both FIT and colonoscopy screening strategies were jointly modeled (Supplementary analysis), the optimal screening strategy was annual FIT between age 35 and 75 years with an ICER of $\$ 47,000$ per LYG (Table 2) for nontransplant individuals with cystic fibrosis. When compared with no screening, it could prevent $31 \%$ of CRC cases and $78 \%$ of the CRC deaths (16 CRC cases and 15 deaths per 1,000). FIT was also cost-effective for cystic fibrosis individuals who had undergone organ transplant with annual FIT between ages 30 and 60, achieving a reduction in CRC incidence of $20 \%$ and mortality of $77 \%$ with an ICER of $\$ 86,000$ per LYG (Table 3).

Table 1. Number of Colorectal Cancer (CRC) Deaths Predicted, Prevented, and Screening LYG Estimated With Microsimulation Screening Analysis-Colon Model Without Screening and With Recommended Screening Scenarios for the US General Population, for Transplant and Non-transplant cystic fibrosis patients

\begin{tabular}{|c|c|c|c|c|}
\hline Screening strategies & CRC deaths predicted ${ }^{a}$ & CRC deaths prevented ${ }^{a}$ & Reduction in CRC mortality (\%) & $\mathrm{LYG}^{a, b}$ \\
\hline \multicolumn{5}{|l|}{ US general population: } \\
\hline Without screening & 27.8 & - & - & - \\
\hline \multicolumn{5}{|l|}{ No transplant CF patients: } \\
\hline Without screening & 19.1 & - & - & - \\
\hline Colonoscopy, Ages 50-75 (10) & 6.5 & 12.6 & 66.0 & 30.3 \\
\hline Colonoscopy, Ages 50-75 (10) & 13.6 & 8.7 & 39.0 & 14.5 \\
\hline
\end{tabular}




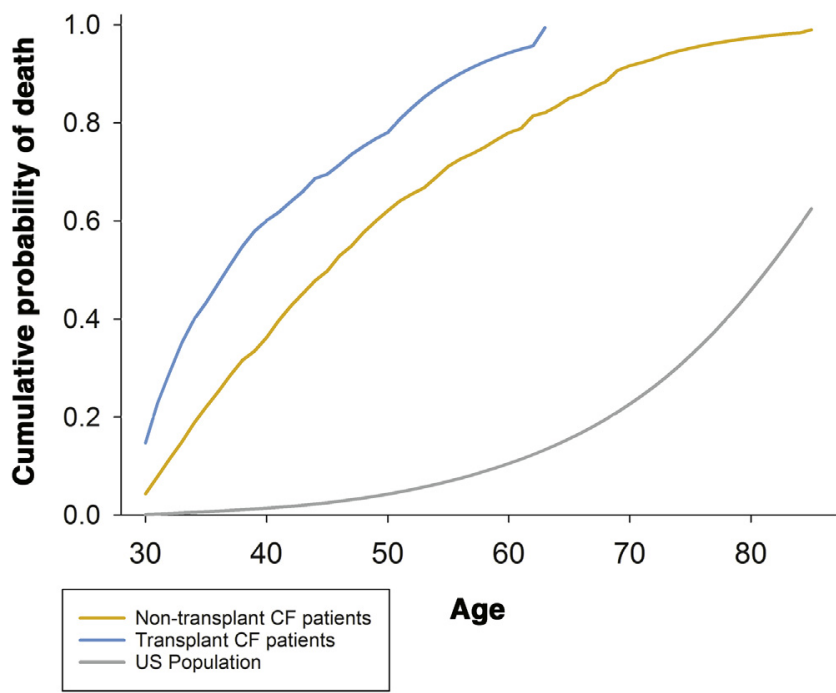

Figure 2. Cumulative risk (\%) of death for all causes simulated with MISCAN-Colon model for US general population, transplant, and non-transplant cystic fibrosis patients without screening. CF, cystic fibrosis.

\section{Sensitivity Analyses}

For many of the sensitivity analyses, the optimal screening strategy remained the same as the base case (Table 4). For non-transplant individuals with cystic fibrosis, the optimal age to stop colonoscopy screening was sensitive to our assumptions for higher all-cause mortality in older ages (55 years) or increased risk of cardiovascular complications (70 years). A colonoscopy screening interval of every 3 years was more optimal when adenoma dwell time was reduced and CRC risk was increased with more proximal adenoma location. Higher costs for colonoscopy (more time required for patients to be prepared for colonoscopy and to recover from its complications) resulted in a later age to start screening (45 years). When all strategies were investigated (Supplementary analysis), FIT start age was earlier (30 years) when adenoma dwell time was shortened and CRC risk was increased. A reduction in specificity and sensitivity of FIT increased the age of starting screening to 40 years. FIT screening should stop at age 60 , when higher overall mortality was assumed among individuals with cystic fibrosis in older ages. FIT was not cost-effective when a biennial interval was considered.

Among transplant cystic fibrosis patients, less intense colonoscopy screening (every 5 years) was optimal when higher patient time costs were considered. For individuals with cystic fibrosis who had an organ transplant before age 30, colonoscopy screening was optimal from 30 years. However, optimal screening interval varied according to the age at organ transplant: every 10 years up to age 55 for those with transplantation at age 20; and every 5 years up to age 55 for those who had a transplant at age 25 . When we assumed that older individuals with cystic fibrosis who had an organ transplant ( $\geq 50$ years) had the same overall mortality as the non-transplant, the age to stop screening increased to 60 years of age. Considering all screening strategies (Supplementary analysis), FIT screening was not
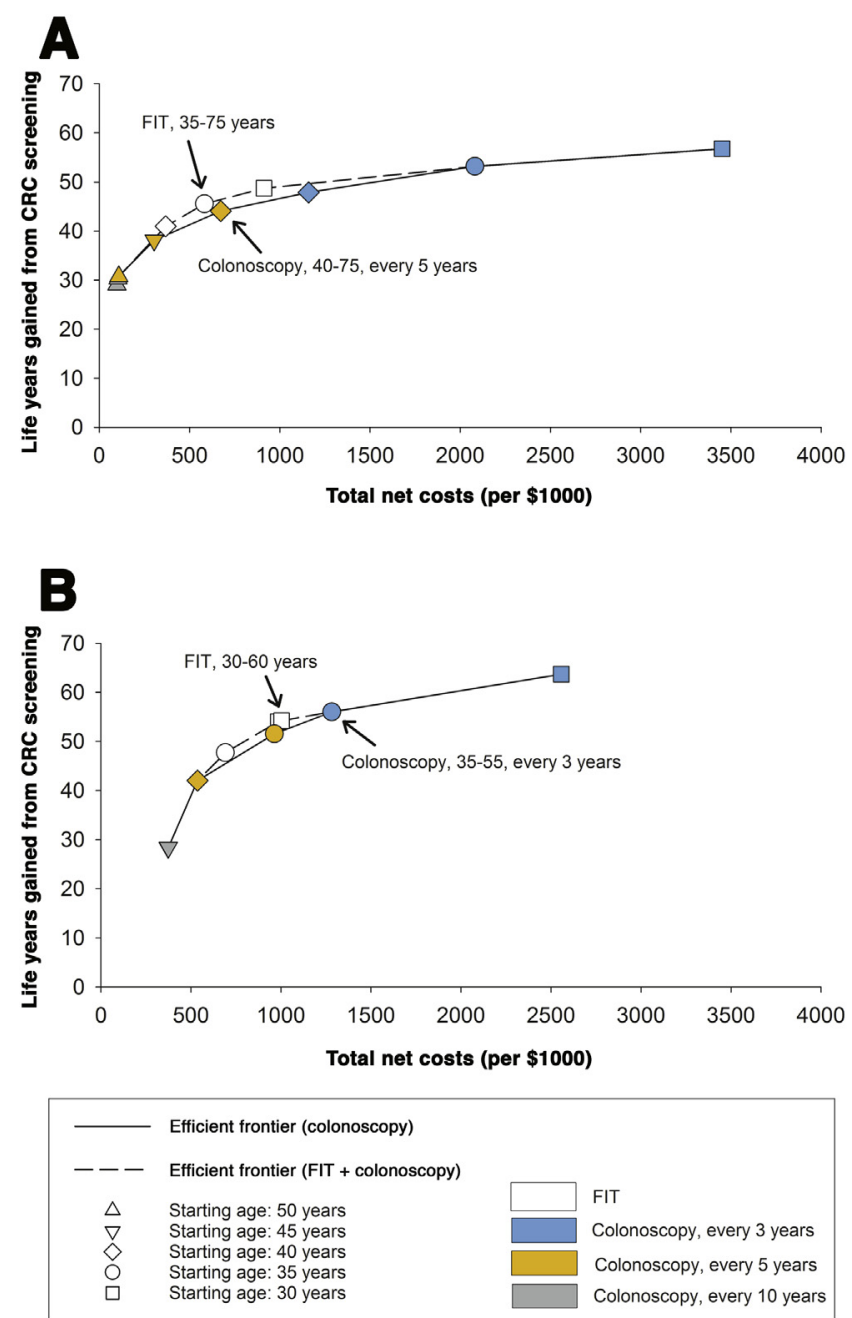

Figure 3. Efficient frontiers with efficient screening strategies for non-transplant cystic fibrosis and transplant cystic fibrosis patients. Total costs and LYG from screening were discounted (3\% discounting rate) and 100\% adherence was assumed for screening, diagnostic, and surveillance test. Optimal screening strategies are labelled and indicated by arrows.

considered cost-effective when there was an increased CRC risk (45-fold), a shorter adenoma dwell time, biennial FIT, lower FIT sensitivity and specificity, and when the same age-specific mortality of non-transplant cystic fibrosis individuals (for those older than 50 years) were assumed for transplant cystic fibrosis patients. Optimal screening strategies among these individuals also varied according the age of organ transplant: FIT screening should start at age 25 when individuals with cystic fibrosis underwent transplantation at age 20 or 25 years.

\section{Discussion}

Recent studies have highlighted the necessity of tailored CRC screening for individuals with cystic fibrosis, reporting that these individuals have an increased risk of CRC compared with the average population. ${ }^{5-8}$ Using an established micro-simulation model, adjusted for the 
Table 2. Efficient Screening Strategies Among Non-Transplant Cystic Fibrosis Patients According to Screening Tests Used

Outcomes per 1,000 non-transplant cystic fibrosis individuals free of diagnosed cancer at age 30 years in 2017 (3\% discounted)

\begin{tabular}{|c|c|c|c|c|c|c|c|c|c|c|c|c|c|}
\hline \multicolumn{2}{|c|}{ Screening tests } & \multirow[b]{2}{*}{$\begin{array}{c}\text { Surveillance } \\
\text { COLs }\end{array}$} & \multirow[b]{2}{*}{$\begin{array}{l}\text { Total } \\
\text { COLs }\end{array}$} & \multirow[b]{2}{*}{ Complications } & \multirow[b]{2}{*}{$\begin{array}{c}\text { CRC } \\
\text { cases }^{c}\end{array}$} & \multirow[b]{2}{*}{$\begin{array}{c}\text { CRC } \\
\text { death }^{a, c}\end{array}$} & \multirow[b]{2}{*}{$\begin{array}{l}\text { LY with } \\
\text { CRC }\end{array}$} & \multirow[b]{2}{*}{$\mathrm{LYG}^{b}$} & \multirow[b]{2}{*}{$\begin{array}{c}\text { Total costs } \\
(\$ 1,000)\end{array}$} & \multirow[b]{2}{*}{$\begin{array}{c}\text { Net costs } \\
(\$ 1,000)\end{array}$} & \multicolumn{2}{|c|}{ Reductions $^{b}(\%)$} & \multirow[b]{2}{*}{$\begin{array}{c}\text { ICER } \\
(\$ 1,000)\end{array}$} \\
\hline FIT & COLs & & & & & & & & & & $\begin{array}{c}\text { CRC } \\
\text { incidence }\end{array}$ & $\begin{array}{c}\text { CRC } \\
\text { mortality }^{c}\end{array}$ & \\
\hline
\end{tabular}

Colonoscopy strategies
(main analysis)

No screening

COL 50-55 y, 10 y

COL 50-60 y, 10 y

COL 50-60 y, 5 y

COL 50-70 y, 5 y

COL 45-75 y, 5 y

COL 40-70 y, 5 y

COL 40-75 y, 5 y

COL $40-75$ y, 3 y

COL 35-75 y, 3 y

COL 30-75 y, 3 y

COLs Complications cases $^{c}$ death $^{a, c}$

$(\$ 1,000)$

$(\$ 1,000)$ incidence $^{C}$ mortality $^{C}(\$ 1,000)$

All screening strategies

(supplementary analysis)

\section{No screening}

COL 50-55 y, 10 y

COL 50-60 y, 10 y

COL 50-60 y, 5 y

COL 50-70 y, 5 y

FIT $40-75$ y

FIT 35-75 y

FIT 30-75 y

COL 35-75 y, 3 y

COL 30-75 y, 3 y

$\begin{array}{rrrr}0 & 0 & 0 & 23 \\ 0 & 214 & 334 & 558 \\ 0 & 225 & 345 & 579 \\ 0 & 234 & 354 & 597 \\ 0 & 235 & 354 & 598 \\ 0 & 394 & 531 & 931 \\ 0 & 689 & 724 & 1417 \\ 0 & 689 & \mathbf{7 2 4} & \mathbf{1 4 1 7} \\ 0 & 793 & 1301 & 2097 \\ 0 & 1482 & 1700 & 3185 \\ 0 & 2671 & 2062 & 4734\end{array}$

0
3
3
3
3
3
4
4
5
5
6

$\begin{array}{rrrr}52 & 19 & 134 & \\ 32 & 7 & 127 & 29 \\ 31 & 7 & 127 & 30 \\ 31 & 6 & 126 & 31 \\ 31 & 6 & 126 & 31 \\ 27 & 5 & 117 & 38 \\ 25 & 4 & 109 & 44 \\ 25 & 4 & 109 & 44 \\ 20 & 3 & 93 & 48 \\ 18 & 2 & 84 & 53 \\ 17 & 2 & 77 & 57\end{array}$

$\begin{array}{rr}1918 & 0 \\ 2016 & 97 \\ 2021 & 103 \\ 2025 & 107 \\ 2026 & 107 \\ 2222 & 303 \\ 2591 & 673 \\ 2591 & 673 \\ 3078 & 1159 \\ 4000 & 2082 \\ 5370 & 3451\end{array}$

0
38
40
41
41
48
52
52
63
67
68

$\begin{array}{rr}0 & - \\ 62 & 3 \\ 66 & 4 \\ 67 & 9 \\ 67 & 14 \\ 74 & 27 \\ 79 & 62 \\ 79 & 84 \\ 84 & 128 \\ 88 & 174 \\ 90 & 383\end{array}$

$\begin{array}{rrrr}0 & 0 & 0 & 23 \\ 0 & 214 & 334 & 558 \\ 0 & 225 & 345 & 579 \\ 0 & 234 & 354 & 597 \\ 0 & 235 & 354 & 598 \\ 4125 & 0 & 300 & 519 \\ 6772 & 0 & 367 & 675 \\ 10,783 & 0 & 427 & 872 \\ 0 & 1482 & 1700 & 3185 \\ 0 & 2671 & 2062 & 4734\end{array}$

$\begin{array}{rrrrrrrrr}52 & 19 & 134 & 0 & 1918 & 0 & 0 & 0 & - \\ 32 & 7 & 127 & 29 & 2016 & 97 & 38 & 62 & 3 \\ 31 & 7 & 127 & 30 & 2021 & 103 & 40 & 66 & 4 \\ 31 & 6 & 126 & 31 & 2025 & 107 & 41 & 67 & 9 \\ 31 & 6 & 126 & 31 & 2026 & 107 & 41 & 67 & 14 \\ 38 & 5 & 164 & 41 & 2286 & 368 & 28 & 75 & 25 \\ \mathbf{3 6} & \mathbf{4} & \mathbf{1 6 3} & \mathbf{4 6} & \mathbf{2 5 0 1} & \mathbf{5 8 3} & \mathbf{3 1} & \mathbf{7 8} & \mathbf{4 7} \\ 36 & 4 & 163 & 49 & 2830 & 912 & 32 & 80 & 103 \\ 18 & 2 & 84 & 53 & 4000 & 2082 & 67 & 88 & 263 \\ 17 & 2 & 77 & 57 & 5370 & 3451 & 68 & 90 & 383\end{array}$

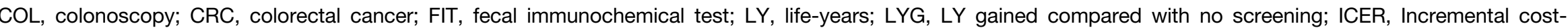
effectiveness ratio (costs/LYs gained).

NOTE. Bold rows indicate optimal screening strategies.

ancluding deaths from complications of screening.

${ }^{b}$ Compared with no screening.

${ }^{c} \mathrm{CRC}$ cases and CRC death were not discounted. 
Table 3. Efficient Screening Strategies Among Transplant Cystic Fibrosis Patients According to Screening Tests Used

Outcomes per 1,000 transplant cystic fibrosis individuals free of diagnosed cancer at age 30 years in 2017 (with organ transplant at age $30,3 \%$ discounted)

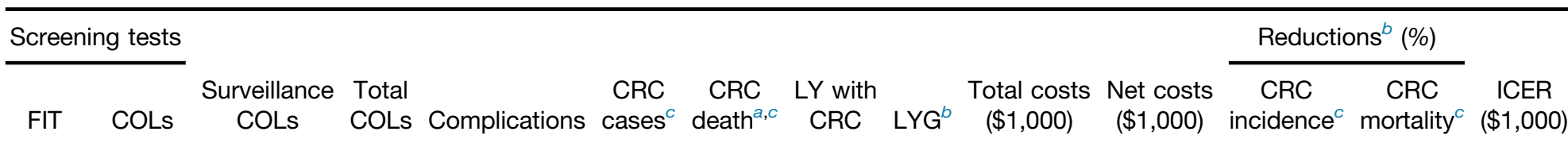

Colonoscopy strategies (main analysis) No screening

COL 45-55 y, 10 y

COL $45-55$ y, 5 y

COL 40-55 y, 5 y

COL 35-55 y, 5 y

COL 35-55 y, 3 y

COL 30-55 y, 3 y

All screening strategies

(supplementary analysis)

No screening

COL 45-55 y, 10 y

COL 45-55 y, 5 y

COL $40-55$ y, 5 y

FIT 35-55 y

FIT 30-55 y

FIT 30-60 y

COL 35-55 y, 3 y

COL $30-55$ y, 3 y

$\begin{array}{rrrr}0 & 0 & 0 & 30 \\ 0 & 199 & 342 & 553 \\ 0 & 200 & 343 & 554 \\ 0 & 324 & 591 & 923 \\ 0 & 607 & 838 & 1,451 \\ 0 & 642 & \mathbf{1 , 2 6 5} & \mathbf{1 , 9 1 2}\end{array}$

$\begin{array}{rl}30 & 0 \\ 553 & 2 \\ 554 & 2 \\ 923 & 3 \\ 451 & 3 \\ 912 & 4 \\ 340 & 5\end{array}$

$\begin{array}{rr}52 & 22 \\ 39 & 9 \\ 39 & 9 \\ 34 & 7 \\ 31 & 5 \\ 26 & 4 \\ 25 & 3\end{array}$

$\begin{array}{rrr}115 & 0 & 2,065 \\ 139 & 28 & 2,438 \\ 139 & 28 & 2,439 \\ 129 & 42 & 2,601 \\ 122 & 52 & 3,028 \\ \mathbf{1 1 0} & \mathbf{5 6} & \mathbf{3 , 3 4 7} \\ 99 & 64 & 4,622\end{array}$

0
374
374
536
963
$\mathbf{1 , 2 8 2}$
2,558

0
25
25
36
41
49
53

$\begin{array}{rr}0 & - \\ 57 & 1 \\ 58 & 7 \\ 70 & 12 \\ 77 & 45 \\ 82 & 71 \\ 87 & 166\end{array}$

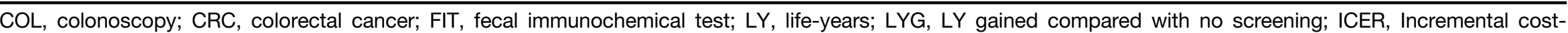
effectiveness ratio (costs/LYs gained).

NOTE. Bold rows indicate optimal screening strategies.

${ }^{a}$ Including deaths from complications of screening.

${ }^{b}$ Compared with no screening.

${ }^{c} \mathrm{CRC}$ cases and CRC death were not discounted. 
Table 4. The Optimal Screening Strategies in Base Case and Sensitivity Analyses for Transplant and Non-transplant Cystic Fibrosis Individuals

\begin{tabular}{|c|c|c|c|c|}
\hline \multirow[b]{2}{*}{$\begin{array}{l}\text { Assumptions } \\
\text { for the sensitivity analyses }\end{array}$} & \multicolumn{2}{|c|}{$\begin{array}{l}\text { Non-transplant } \\
\text { CF patients }\end{array}$} & \multicolumn{2}{|c|}{$\begin{array}{l}\text { Transplant } \\
\text { CF patients }\end{array}$} \\
\hline & $\begin{array}{l}\text { Colonoscopy } \\
\text { (main analysis) }\end{array}$ & $\begin{array}{l}\text { All tests } \\
\text { (supplementary } \\
\text { analysis) }\end{array}$ & $\begin{array}{l}\text { Colonoscopy } \\
\text { (main analysis) }\end{array}$ & $\begin{array}{l}\text { All tests } \\
\text { (supplementary } \\
\text { analysis) }\end{array}$ \\
\hline Base case & $\begin{array}{c}\text { COL } \\
40-75(5)\end{array}$ & $\begin{array}{l}\text { FIT } \\
35-75\end{array}$ & $\begin{array}{c}\text { COL } \\
35-55(3)\end{array}$ & $\begin{array}{c}\text { FIT } \\
30-60\end{array}$ \\
\hline $\begin{array}{l}\text { Worst-case } \\
\text { sensitivity for colonoscopy test }\end{array}$ & B & B & B & B \\
\hline More proximal adenoma location & $\mathrm{B}$ & $\mathrm{B}$ & B & B \\
\hline $\begin{array}{l}\text { Higher rates } \\
\text { of colonoscopy complications }\end{array}$ & $\mathrm{B}$ & B & B & B \\
\hline $\begin{array}{l}\text { Higher rates } \\
\text { of cardiovascular complications } \\
\quad(5 \text {-fold increased) }\end{array}$ & $\begin{array}{c}\text { COL } \\
40-70(5)\end{array}$ & $\mathrm{B}$ & B & B \\
\hline $\begin{array}{l}\text { Higher rates } \\
\text { of cardiovascular complications } \\
\quad(10 \text {-fold increased) }\end{array}$ & $\begin{array}{c}\text { COL } \\
40-70(5)\end{array}$ & B & B & B \\
\hline Worst-case specificity for FIT (0.90) & B & B & B & B \\
\hline $\begin{array}{l}\text { Worst-case for } \\
\text { specificity }(0.75) \text { and sensitivity } \\
\quad(36 \% \text { reduced }) \text { for FIT }\end{array}$ & B & $\begin{array}{l}\text { FIT } \\
40-75\end{array}$ & B & $\begin{array}{c}\mathrm{COL} \\
35-55(3)\end{array}$ \\
\hline Biennial screening intervals for FIT & B & $\begin{array}{c}\mathrm{COL} \\
40-75(5)\end{array}$ & B & $\begin{array}{c}\mathrm{COL} \\
35-55(3)\end{array}$ \\
\hline Lower adherence for screening tests & $\mathrm{B}$ & B & B & B \\
\hline Intensive surveillance & B & $\mathrm{B}$ & B & B \\
\hline Higher patient time costs & $\begin{array}{c}\mathrm{COL} \\
45-75(5)\end{array}$ & B & $\begin{array}{c}\mathrm{COL} \\
35-55(5)\end{array}$ & $\begin{array}{l}\text { FIT } \\
30-55\end{array}$ \\
\hline \multicolumn{5}{|l|}{ Only for no transplant CF patients } \\
\hline $\begin{array}{l}\text { Increased CRC risk with more } \\
\text { proximal adenoma location } \\
\text { (10-fold increased risk) }\end{array}$ & $\begin{array}{c}\text { COL } \\
40-75(3)\end{array}$ & $\begin{array}{c}\text { FIT } \\
30-75\end{array}$ & - & - \\
\hline $\begin{array}{l}\text { Shorter adenoma dwelling time } \\
\quad(94 \% \text { reduced })\end{array}$ & $\begin{array}{c}\mathrm{COL} \\
40-70(3)\end{array}$ & $\begin{array}{l}\text { FIT } \\
30-75\end{array}$ & - & - \\
\hline $\begin{array}{l}\text { Higher overall mortality in older } \\
\text { ages ( } \geq 45 \text { years) } \\
\text { Only for transplant } \text { CF patients }\end{array}$ & $\begin{array}{c}\text { COL } \\
40-55(5)\end{array}$ & $\begin{array}{c}\text { FIT } \\
35-60\end{array}$ & - & - \\
\hline Organ transplant at: & & & & \\
\hline Age 20 & - & - & $\begin{array}{c}\mathrm{COL} \\
30-55(10)\end{array}$ & $\begin{array}{c}\text { FIT } \\
25-55\end{array}$ \\
\hline Age 25 & - & - & $\begin{array}{c}\mathrm{COL} \\
30-55(5)\end{array}$ & $\begin{array}{c}\text { FIT } \\
25-55\end{array}$ \\
\hline $\begin{array}{l}\text { Additional colonoscopy screening } \\
\text { strategy (every } 5 \text { years) starting } \\
\text { at age } 32 \text { for transplant patients } \\
\text { (organ transplant at age } 30 \text { ) }\end{array}$ & - & - & B & B \\
\hline $\begin{array}{l}\text { Increased CRC risk with more } \\
\text { proximal adenoma location (45- } \\
\text { fold increased risk) }\end{array}$ & - & - & B & $\begin{array}{c}\text { COL } \\
35-55(3)\end{array}$ \\
\hline $\begin{array}{c}\text { Age-specific overall mortality rates of } \\
\text { non-transplant CF after } 50 \text { years }\end{array}$ & - & - & $\begin{array}{c}\mathrm{COL} \\
35-60(3)\end{array}$ & $\begin{array}{c}\mathrm{COL} \\
35-60(3)\end{array}$ \\
\hline $\begin{array}{l}\text { Shorter adenoma dwelling time } \\
\text { (50\% reduced) with adjusted } \\
\text { CRC risk (16-fold increased) }\end{array}$ & - & - & B & $\begin{array}{c}\mathrm{COL} \\
35-55(3)\end{array}$ \\
\hline
\end{tabular}


characteristics of cystic fibrosis populations, we found that the recommended US CRC screening strategy for the general population was not optimal for individuals with cystic fibrosis. A greater reduction in CRC mortality could be achieved if screening started before age 50 in both individuals who have and have not received an organ transplantation. Colonoscopy every 5 years starting at age 40 in individuals with cystic fibrosis who have not received a transplant was shown, in our study, to significantly improve LYG and CRC mortality at an acceptable cost (ICER of $\$ 84,000$ per LYG). Our cost-effectiveness analysis suggests, for cystic fibrosis patients who underwent organ transplantation, more intensive colonoscopy screening starting at ages 30 (transplant at age 20 or 25) or 35 (transplant at age 30 ), through to age 55. The optimal screening interval varied according to age at organ transplant and patient time costs. The model also suggested that screening with FIT could be more cost-effective than colonoscopy (Supplementary analysis), but specific evidence of its performance in the cystic fibrosis population is required before considering this screening modality.

Despite the lower life-expectancy reported in cystic fibrosis population, the model suggests - especially for those who have not undergone organ transplantation - that screening should be repeated until age 75 years. Few individuals with cystic fibrosis currently reach this age, but once they survive to a certain age (ie, 65-70) their excess risk of dying compared with the general population becomes smaller and a death from CRC becomes more likely. Thus, screening is effective until age 75 . However, the model was adjusted to reflect data on individuals with cystic fibrosis provided by the fibrosis Foundation Patient Registry, which contains only a very small number of individuals at older ages. Moreover, a previous study has shown that some death dates were missing in the fibrosis Foundation Patient Registry, especially for individuals with cystic fibrosis older than 45 years, when compared with national vital statistics. ${ }^{45}$ Therefore, the model results on the age to stop screening could be less robust than those obtained on the age to start screening. A specific sensitivity analysis, carried out assuming a higher overall mortality in cystic fibrosis long-term survivors as reported by Nick et al in Colorado, ${ }^{45}$ confirmed this hypothesis (Table 4). This potentially incomplete ascertainment of outcomes may also affect estimates for CRC incidence. In that case, we would have underestimated the risk of CRC and the optimal colonoscopy screening strategy would be even more intensive than the base case: colonoscopy screening should start at age 40 and repeated every 3 years.

At the same time, our model suggests to screen individuals with cystic fibrosis who have had an organ transplant up to age 55. This difference is mainly related to the higher CRC risk seen in cystic fibrosis individuals after transplantation. Performing our analysis on transplant cystic fibrosis individuals (assuming transplant at age 30 years), the model predicted that all these patients developed 1 or more adenomas before age 55 and, therefore, entered colonoscopy surveillance rather than attending subsequent screening rounds. As a result, outcomes of similar strategies with different ages to stop screening, above age 60 , were the same (Supplementary Tables 5-6). Although individuals with cystic fibrosis had a more frequent adenoma onset after organ transplant, the increase in CRC incidence was not as immediate, potentially because of the lag-time in the progression between adenoma and CRC. ${ }^{46}$ This was shown in our analysis for starting screening age in transplant cystic fibrosis patients that underwent organ transplant at age 30 .

Specific screening recommendations already exist for several groups of individuals at higher risk of CRC: individuals with family history of CRC (first-degree relative) are recommended to undergo colonoscopy every 5-10 years, starting at age $40 .{ }^{47}$ Individuals with Lynch syndrome should undergo colonoscopy every 1-2 years starting at age 20-25 years. ${ }^{48}$ CRC risk in the cystic fibrosis population falls somewhere between the risk of these different groups, with the risk in transplant patients (30-fold increase compared with general population) ${ }^{6}$ being higher than Lynch syndrome patients. ${ }^{49}$ This indicates that individuals with cystic fibrosis should potentially have similar recommendations as these other high-risk groups. However, it is also necessary to consider the different life expectancy of individuals with cystic fibrosis compared with individuals in other high-risk groups because this may influence the balance between the harms and benefits of screening. This effect may be seen in Table 1. Although patients with cystic fibrosis have an up to 30-fold increased CRC risk compared with average US individuals, CRC deaths predicted among them were less than reported for the US general population (19.1 and 22.3 vs 27.8 per 1000 ) because of their more elevated 'other cause' mortality $(70 \%$ of the deaths in cystic fibrosis individuals are related to cardiorespiratory causes). ${ }^{4}$ While early diagnosis may prevent a CRC death, screening may result in an over-diagnosis because of cystic fibrosis-related competing causes of death, and can incur in additional costs from screening and treatment. Thus, CRC screening guidelines for the other high-risk group cannot be simply generalized to individuals with cystic fibrosis. This may explain why, unlike for individuals with Lynch syndrome, more intensive screening strategies were not found to be cost-effective for the cystic fibrosis population.

Several studies have recently highlighted the necessity of tailored CRC screening for the cystic fibrosis population ${ }^{5-8}$ and, to our knowledge, this is the first study to assess the cost-effectiveness of CRC screening in these individuals. The results of this formal decision analysis, which was requested by the Cystic Fibrosis Foundation and cystic Fibrosis Foundation and Cystic Fibrosis CRC Screening Task Force to inform the cystic fibrosis CRC screening consensus recommendations ${ }^{19}$ have provided important suggestions for clinicians, researchers, and policy makers who were tasked with developing an appropriate CRC screening policy for people with cystic fibrosis in the US. However, the findings of this study should be interpreted with caution considering the following limitations. First, we did not model the natural history of CRC separately for men and women. Epidemiological studies among cystic fibrosis patients report gender differences: women experience a lower risk of developing $\mathrm{CRC}^{6}$ and lower life-expectancy ${ }^{50}$ than men. Considering 
these differences, a less intensive CRC screening strategy could be optimal for women with cystic fibrosis. However, there is little data on CRC incidence and mortality in these patients and even less is stratified by gender, meaning this differentiation is not yet feasible. Second, our analysis was not stratified for pulmonary function (an important clinical indicator of the health of individuals with cystic fibrosis). Although Niccum and colleagues ${ }^{8}$ only considered cystic fibrosis patients with predicted FEV1 $\geq 40 \%$ eligible to CRC screening, the available data for individuals with cystic fibrosis did not permit this additional model stratification. The most recent Cystic Fibrosis Patient Registry Annual Report showed that up to $75 \%$ of individuals with cystic fibrosis aged 40 years had a predicted FEV1 $\geq 40 \%{ }^{4}$ If screening was limited to this subset of individuals, the balance between harms and benefits of screening in individuals with cystic fibrosis would become more favorable.

Furthermore, we assumed that adenomas in persons with cystic fibrosis could arise following the same localization-specific distribution observed in autopsy studies for the general population ${ }^{24-33}$ and with the same increased risk - 7-fold compared with the general population - in both the colon and rectum. Although Maisonneuve and colleagues ${ }^{6}$ reported that CRC cases were mainly located in the colon of individuals with cystic fibrosis $(26$ out 28 cases), a direct calibration of the adenoma localization-specific onset distribution was not possible because limited data is currently available. To address this, we performed a sensitivity analysis to assess the effects of assuming a different localization-specific distribution for adenoma onset in people with cystic fibrosis and screening strategy outcomes were not sensitive to this assumption (Table 4).

Several factors may cause the higher risk of CRC in the cystic fibrosis population, but information about the rationale of this increased risk remains unclear. We assumed that the higher risk of CRC shown in the cystic fibrosis population was because of a more frequent adenoma onset. This assumption was validated for non-transplant patients, but not for individuals with cystic fibrosis who had an organ transplant (Supplementary Figure 3). A shorter adenoma dwell time may also play a role in the progression from adenoma to CRC. To investigate this, we performed a specific sensitivity analysis assuming a shorter dwell time $(50 \%$ reduced, faster adenoma progression) and more elevated adenoma onset (16-fold increased risk) for transplant cystic fibrosis patients. The results of this sensitivity analysis were validated with adenoma detection rates observed in an observational study of cystic fibrosis patients undergoing colonoscopy screening (Supplementary Figure 3). ${ }^{8}$ However, this analysis revealed that our cost-effectiveness outcomes were not sensitive to this assumption. Our model does not explicitly describe adenoma histology and that may explain the lower simulated rates of colonoscopy-detected advanced adenomas (Supplementary Figure 3).

In our study, assumptions on colonoscopy performance, complications, polypectomy safety, costs (including sedation costs), and adverse events of bowel preparation were informed by data from the general population and the
Medicare population ${ }^{40}$ because specific empirical data for the cystic fibrosis population were not available. For colonoscopy performance, this assumption seems reasonable because model-predicted adenoma detection rates were close to observed (Supplementary Figure 3). However, it may be reasonable to assume that risk of complications and/or inadequate bowel preparation is higher in people with cystic fibrosis compared with the general population. Also, the more intensive and extended bowel preparation regimens for individuals with cystic fibrosis and additional colonoscopy investigations because of inadequate bowel preparation could lead to a further increase in adverse events. To address this concern, we performed specific sensitivity analyses on colonoscopy performance and rate of complications (especially for cardiovascular adverse events, including respiratory arrest, Supplementary Tables 7 and 8). Results of these analyses showed that the optimal screening starting ages and intervals were not sensitive to changes in these assumptions (Table 4).

The feasibility of colonoscopy in individuals with cystic fibrosis and its capacity to early detect CRC and adenomas in these individuals was suggested by the findings of a small observational study conducted in Minnesota. ${ }^{8}$ Moreover, colonoscopy is the screening test of choice for higher-risk groups. ${ }^{47,48}$ We therefore focused our main analysis and interpretation of our results on this screening modality. However, given the potential burden of colonoscopy and colonoscopy preparation to the cystic fibrosis patient, we believe it was pertinent to also consider FIT as a possible and hypothetically adequate alternative. As such, we performed a specific supplementary analysis including annual FIT screening. We found that this screening modality was cost-effective and optimal among individuals with cystic fibrosis. However, because information on FIT characteristics in this population is lacking, the analysis was performed using FIT characteristics from the general population. ${ }^{37}$ In individuals with cystic fibrosis, the presence of blood in feces could be related to several gastrointestinal disorders, ${ }^{51}$ which could affect the effectiveness and cost-effectiveness of FIT screening in the cystic fibrosis population. Sensitivity analyses revealed that our results on cost-effectiveness of FIT depend on screening intensity and the test characteristics as assumed in this analysis, especially for post-transplant cystic fibrosis patients. Hence, before considering FIT as the preferred screening modality, FIT performance must be tested in the cystic fibrosis population to better explore its effectiveness in early detection of CRC and adenomas among this population. If future studies confirm that FIT in individuals with cystic fibrosis performs as well as or better than we assumed in our sensitivity analyses, FIT may be considered an attractive screening option for this population. In the meantime, FIT could be considered for those not willing to undergo colonoscopy.

Despite its limitations, this study has important clinical and policy implications. This study indicates that there is benefit to earlier CRC screening in the cystic fibrosis population and can be done at acceptable costs. The findings of this analysis support clinicians, researchers, and policy makers who aim to define a tailored CRC screening for 
individuals with cystic fibrosis in the US. Meanwhile, outcomes of screening in individuals with cystic fibrosis should be closely monitored to accumulate evidence on the performance and safety of CRC screening in these individuals.

\section{Supplementary Material}

Note: To access the supplementary material accompanying this article, visit the online version of Gastroenterology at www.gastrojournal.org, and at https://doi.org/10.1053/ j.gastro.2017.10.036.

\section{References}

1. Parkins MD, Parkins VM, Rendall JC, et al. Changing epidemiology and clinical issues arising in an ageing cystic fibrosis population. Ther Adv Respir Dis 2011; 5:105-119.

2. Farrell PM. The prevalence of cystic fibrosis in the European Union. J Cyst Fibros 2008;7:450-453.

3. Knapp EA, Fink AK, Goss CH, et al. The Cystic Fibrosis Foundation Patient Registry. Design and methods of a national observational disease registry. Ann Am Thorac Soc 2016;13:1173-1179.

4. Cystic Fibrosis Foundation. Cystic Fibrosis Foundation Patient Registry 2015 Annual Data Report. Bethesda, Maryland. 2016. Available at: https://www.cff.org/OurResearch/CF-Patient-Registry/2015-Patient-RegistryAnnual-Data-Report.pdf.

5. Billings JL, Dunitz JM, McAllister S, et al. Early colon screening of adult patients with cystic fibrosis reveals high incidence of adenomatous colon polyps. J Clin Gastroenterol 2014;48:e85-e88.

6. Maisonneuve P, Marshall BC, Knapp EA, et al. Cancer risk in cystic fibrosis: a 20-year nationwide study from the United States. J Natl Cancer Inst 2013;105:122-129.

7. Meyer KC, Francois ML, Thomas HK, et al. Colon cancer in lung transplant recipients with CF: increased risk and results of screening. J Cyst Fibros 2011;10:366-369.

8. Niccum DE, Billings JL, Dunitz JM, et al. Colonoscopic screening shows increased early incidence and progression of adenomas in cystic fibrosis. J Cyst Fibros 2016;15:548-553.

9. Atkin WS, Edwards R, Kralj-Hans I, et al. Once-only flexible sigmoidoscopy screening in prevention of colorectal cancer: a multicentre randomised controlled trial. Lancet 2010;375:1624-1633.

10. Hardcastle JD, Chamberlain JO, Robinson MH, et al. Randomised controlled trial of faecal-occult-blood screening for colorectal cancer. Lancet 1996;348:14721477.

11. Jorgensen OD, Kronborg O, Fenger C. A randomised study of screening for colorectal cancer using faecal occult blood testing: results after 13 years and seven biennial screening rounds. Gut 2002;50:29-32.

12. Lansdorp-Vogelaar I, van Ballegooijen M, Boer R, et al. A novel hypothesis on the sensitivity of the fecal occult blood test: results of a joint analysis of 3 randomized controlled trials. Cancer 2009;115:2410-2419.
13. Zauber AG, Winawer SJ, O'Brien MJ, et al. Colonoscopic polypectomy and long-term prevention of colorectalcancer deaths. N Engl J Med 2012;366:687-696.

14. Mandel JS, Church TR, Ederer F, et al. Colorectal cancer mortality: effectiveness of biennial screening for fecal occult blood. J Natl Cancer Inst 1999;91:434-437.

15. Holme Ø, Løberg $\mathbf{M}$, Kalager $\mathbf{M}$, et al. Effect of flexible sigmoidoscopy screening on colorectal cancer incidence and mortality: a randomized clinical trial. JAMA 2014; 312:606-615.

16. Schoen RE, Pinsky PF, Weissfeld JL, et al. Colorectalcancer incidence and mortality with screening flexible sigmoidoscopy. New Engl J Med 2012;366:2345-2357.

17. Segnan N, Armaroli P, Bonelli L, et al. Once-only sigmoidoscopy in colorectal cancer screening: follow-up findings of the Italian randomized controlled trial SCORE. J Natl Cancer Inst 2011;103:1310-1322.

18. Lieberman DA, Rex DK, Winawer SJ, et al. Guidelines for colonoscopy surveillance after screening and polypectomy: a consensus update by the US Multi-Society Task Force on Colorectal Cancer. Gastroenterology 2012;143:844-857.

19. Hadjiliadis D, Khoruts A, Zauber AG, et al; on behalf of the Cystic Fibrosis Colorectal Cancer Screening Task Force. Cystic fibrosis colorectal cancer screening consensus recommendations. Gastroenterology 2018;154:736-745.

20. Vogelaar I, van Balegooijen M, Zauber AG, et al. Model profiler of the MISCAN-Colon miscosimulation model for colorectal cancer. Department of Public Health, Erasmus MC. 2004. Available at: http://cisnet.flexkb.net/mp/pub/ cisnet_colorectal_sloankettering_profile.pdf.

21. van Hees F, Habbema JD, Meester RG, et al. Should colorectal cancer screening be considered in elderly persons without previous screening? A cost-effectiveness analysis. Ann Intern Med 2014;160:750-759.

22. Rutter CM, Johnson EA, Feuer EJ, et al. Secular trends in colon and rectal cancer relative survival. J Natl Cancer Inst 2013;105:1806-1813.

23. Surveillance, Epidemiology, and End Results (SEER) Program. SEER ${ }^{\star}$ Stat Database: Incidence-SEER 9 Regs Limited Use, Nov 2002 Sub (1973-2000). National Cancer Institute, DCCPS, Surveillance Research Program, Cancer Statistics Branch. Released April 2003, based on the November 2002 submission.

24. Arminski TC, McLean DW. Incidence and distribution of adenomatous polyps of the colon and rectum based on 1,000 autopsy examinations. Dis Colon Rectum 1964; 7:249-261.

25. Bombi JA. Polyps of the colon in Barcelona, Spain. An autopsy study. Cancer 1988;61:1472-1476.

26. Chapman I. Adenomatous polypi of large intestine: incidence and distribution. Ann Surg 1963;157:223-226.

27. Clark JC, Collan Y, Eide TJ, et al. Prevalence of polyps in an autopsy series from areas with varying incidence of large-bowel cancer. Int J Cancer 1985;36:179-186.

28. Jass JR, Young PJ, Robinson EM. Predictors of presence, multiplicity, size and dysplasia of colorectal adenomas. A necropsy study in New Zealand. Gut 1992; 33:1508-1514. 
29. Johannsen LG, Momsen O, Jacobsen NO. Polyps of the large intestine in Aarhus, Denmark. An autopsy study. Scand J Gastroenterol 1989;24:799-806.

30. LJ B. Polyps of the colon and rectum: incidence and distribution. Dis Colon Rectum 1961;4:277-282.

31. Rickert RR, Auerbach O, Garfinkel L, et al. Adenomatous lesions of the large bowel: an autopsy survey. Cancer 1979;43:1847-1857.

32. Vatn $\mathrm{MH}$, Stalsberg $\mathrm{H}$. The prevalence of polyps of the large intestine in Oslo: an autopsy study. Cancer 1982;49:819-825.

33. Williams AR, Balasooriya BA, Day DW. Polyps and cancer of the large bowel: a necropsy study in Liverpool. Gut 1982;23:835-842.

34. Knudsen AB, Zauber AG, Rutter CM, et al. Estimation of benefits, burden, and harms of colorectal cancer screening strategies: modeling study for the US Preventive Services Task Force. JAMA 2016;315:2595-2609.

35. Belli EV, Landolfo K, Keller C, et al. Lung cancer following lung transplant: single institution 10 year experience. Lung Cancer 2013;81:451-454.

36. van Rijn JC, Reitsma JB, Stoker J, et al. Polyp miss rate determined by tandem colonoscopy: a systematic review. Am J Gastroenterol 2006;101:343-350.

37. Imperiale TF, Ransohoff DF, Itzkowitz SH, et al. Multitarget stool DNA testing for colorectal-cancer screening. N Engl J Med 2014;370:1287-1297.

38. Gatto NM, Frucht H, Sundararajan V, et al. Risk of perforation after colonoscopy and sigmoidoscopy: a populationbased study. J Natl Cancer Inst 2003;95:230-236.

39. Schroy PC 3rd, Coe A, Chen CA, et al. Prevalence of advanced colorectal neoplasia in white and black patients undergoing screening colonoscopy in a safety-net hospital. Ann Intern Med 2013;159:13-20.

40. Warren JL, Klabunde CN, Mariotto AB, et al. Adverse events after outpatient colonoscopy in the Medicare population. Ann Intern Med 2009;150:849-857, W152.

41. Leffler DA, Kheraj R, Garud S, et al. The incidence and cost of unexpected hospital use after scheduled outpatient endoscopy. Arch Intern Med 2010;170:1752-1757.

42. Bureau of Labor Statistics. Current Employment Statistics (National). Available at: www.bls.gov/web/empsit/ ceseesummary.htm. (Accessed August 16, 2016).

43. Yabroff KR, Lamont EB, Mariotto A, et al. Cost of care for elderly cancer patients in the United States. J Natl Cancer Inst 2008;100:630-641.
44. The United States Department of Labor. Bureau of Labor Statistics. Consumer Price Index. Available at: http:// www.bls.gov/cpi/tables.htm.

45. Nick JA, Chacon CS, Brayshaw SJ, et al. Effects of gender and age at diagnosis on disease progression in long-term survivors of cystic fibrosis. Am J Respir Crit Care Med 2010;182:614-626.

46. Morson B. The polyp-cancer sequence in the large bowel. Proc R Soc Med 1974;67:451-457.

47. Levin B, Lieberman DA, McFarland B, et al. Screening and surveillance for the early detection of colorectal cancer and adenomatous polyps, 2008: a joint guideline from the American Cancer Society, the US MultiSociety Task Force on Colorectal Cancer, and the American College of Radiology. CA Cancer J Clin 2008; 58:130-160.

48. Lindor NM, Petersen GM, Hadley DW, et al. Recommendations for the care of individuals with an inherited predisposition to Lynch syndrome: a systematic review. JAMA 2006;296:1507-1517.

49. Bonadona V, Bonaiti B, Olschwang S, et al. Cancer risks associated with germline mutations in MLH1, MSH2, and MSH6 genes in Lynch syndrome. JAMA 2011;305:2304-2310.

50. MacKenzie T, Gifford $A H$, Sabadosa $K A$, et al. Longevity of patients with cystic fibrosis in 2000 to 2010 and beyond: survival analysis of the Cystic Fibrosis Foundation patient registry. Ann Intern Med 2014:161:233-241.

51. Kelly T, Buxbaum J. Gastrointestinal manifestations of cystic fibrosis. Dig Dis Sci 2015;60:1903-1913.

Author names in bold designate shared co-first authorship.

Received February 27, 2017. Accepted October 26, 2017.

Reprint requests

Address requests for reprints to: Andrea Gini, MSc, Department of Public Health, Erasmus Medical Center, P.O. Box 2040, 3000 CA Rotterdam, the Netherlands. e-mail: a.gini@erasmusmc.nl; fax: +31(0)107038475.

\section{Conflicts of interests}

The authors disclose no conflicts.

Funding

This study was funded by the Cystic Fibrosis Foundation (CFF), the Cancer Intervention and Surveillance Modeling Network consortium (CISNET, grant U01CA199335), and Memorial Sloan Kettering Cancer Center Support Grant/ Core Grant (Ann G. Zauber, PhD; P30 CA008748). 
Supplementary Table 1. Test Characteristics of Colonoscopy and Fecal Immunochemical Tests (FIT)

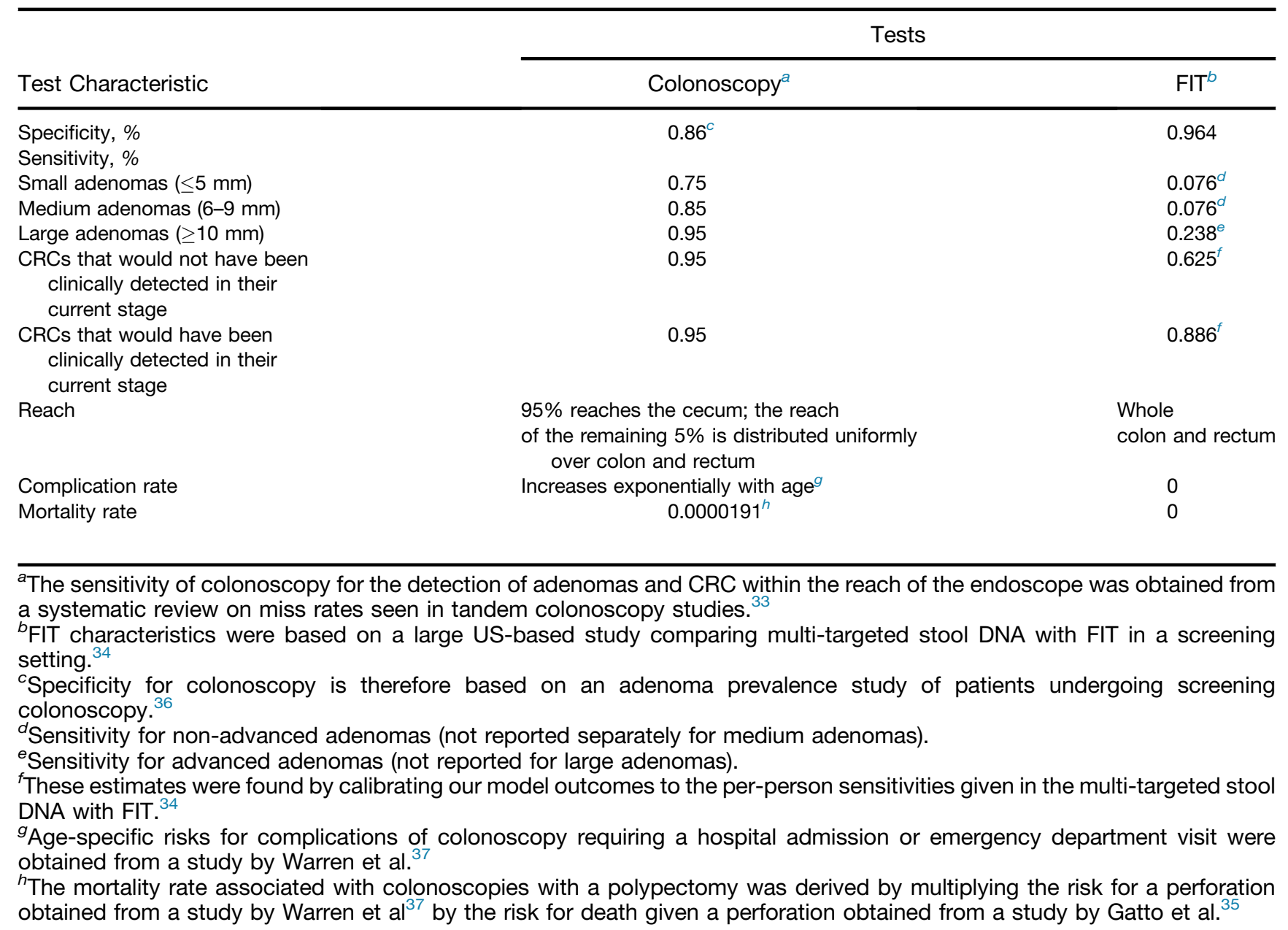


Supplementary Table 2. Costs Associated With Colorectal Cancer Screening in the Base Case and Cost Sensitivity Analysis

\begin{tabular}{|c|c|c|}
\hline & Costs, $\$^{a}$ & $\begin{array}{l}\text { Higher costs for colonoscopy, } \$ \\
\text { (sensitivity analysis) }^{e}\end{array}$ \\
\hline Per FIT & 40 & - \\
\hline \multicolumn{3}{|l|}{ Per colonoscopy } \\
\hline Without polypectomy/biopsy & 880 & 1400 \\
\hline With polypectomy/biopsy & 1200 & 1700 \\
\hline \multicolumn{3}{|l|}{ Per complication of colonoscopy } \\
\hline Serious ${ }^{b}$ Gl complications & 8100 & 11,200 \\
\hline Other ${ }^{c}$ Gl complications & 6200 & 7600 \\
\hline Cardiovascular complications $^{d}$ & 6700 & 8500 \\
\hline \multicolumn{3}{|l|}{ Per LY with CRC care } \\
\hline \multicolumn{3}{|l|}{ Initial care } \\
\hline Stage I CRC & 36,900 & - \\
\hline Stage II CRC & 49,500 & - \\
\hline Stage III CRC & 60,100 & - \\
\hline Stage IV CRC & 78,200 & - \\
\hline \multicolumn{3}{|l|}{ Continuing care } \\
\hline Stage I CRC & 3100 & - \\
\hline Stage II CRC & 2900 & - \\
\hline Stage III CRC & 4100 & - \\
\hline Stage IV CRC & 12,300 & - \\
\hline \multicolumn{3}{|l|}{ Terminal Care, ending in CRC death } \\
\hline Stage I CRC & 64,200 & - \\
\hline Stage II CRC & 63,900 & - \\
\hline Stage III CRC & 67,400 & - \\
\hline Stage IV CRC & 88,900 & - \\
\hline \multicolumn{3}{|c|}{ Terminal Care, ending in other-cause death } \\
\hline Stage I CRC & 19,400 & - \\
\hline Stage II CRC & 17,400 & - \\
\hline Stage III CRC & 21,600 & - \\
\hline Stage IV CRC & 50,200 & - \\
\hline
\end{tabular}

GI, gastrointestinal; FIT, fecal immunochemical test.

${ }^{a}$ Costs are presented in 2015 US dollars and include co-payments and patient time costs (ie, the opportunity costs of spending time on screening or being treated for a complication or $\mathrm{CRC}$ ) but do not include travel costs, costs of lost productivity, and unrelated health care and non-health care costs in added years of life. We assumed that the value of patient time was equal to the median wage rate in 2014: \$17.01/hour. Cost values were estimated for the year 2014. We assumed that FITs, colonoscopies, and complications used up 1, 8, and 16 hours of patient time, respectively. Patient time costs were already included in the estimates for the costs of LYs with CRC care obtained from a study by Yabroff et al. ${ }^{40}$ All costs were adjusted for the year 2015 using the annual average Consumer Price Indexes provided by US Bureau of Labor Statistics. ${ }^{41}$

${ }^{b}$ Serious Gl complications included perforations, gastrointestinal bleeding, or transfusions.

${ }^{c}$ Other GI complications included paralytic ileus, nausea and vomiting, dehydration, or abdominal pain.

${ }^{d}$ Cardiovascular complications included myocardial infarction or angina, arrhythmias, congestive heart failure, cardiac or respiratory arrest, syncope, hypotension, or shock.

eWe assumed that colonoscopies and complications used up 40 and 190 hours of patient time, respectively. 


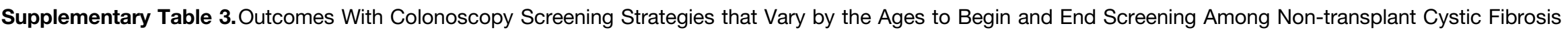
Patients

\begin{tabular}{|c|c|c|c|c|c|c|c|c|c|c|c|c|c|c|}
\hline & \multicolumn{14}{|c|}{ Outcomes per 1000 non-transplant cystic fibrosis individuals free of diagnosed cancer at age 30 years in 2017 (3\% discounted) } \\
\hline & \multicolumn{2}{|c|}{ Screening tests } & \multirow[b]{2}{*}{$\begin{array}{c}\text { Surveillance } \\
\text { COLs }\end{array}$} & \multirow[b]{2}{*}{$\begin{array}{l}\text { Total } \\
\text { COLs }\end{array}$} & \multirow[b]{2}{*}{ Complications } & \multirow[b]{2}{*}{$\begin{array}{c}\text { CRC } \\
\text { cases }^{C}\end{array}$} & \multirow[b]{2}{*}{$\begin{array}{c}\text { CRC } \\
\text { death }^{a, c}\end{array}$} & \multirow[b]{2}{*}{$\begin{array}{l}\text { LY with } \\
\text { CRC }\end{array}$} & \multirow[b]{2}{*}{ LYG $^{b}$} & \multirow[b]{2}{*}{$\begin{array}{c}\text { Total costs } \\
(\$)\end{array}$} & \multirow[b]{2}{*}{$\begin{array}{l}\text { Net costs } \\
(\$)\end{array}$} & \multicolumn{2}{|c|}{ Reductions $^{b}(\%)$} & \multirow[b]{2}{*}{$\begin{array}{l}\text { Efficient } \\
\text { strategy }\end{array}$} \\
\hline & FIT & COLs & & & & & & & & & & $\begin{array}{c}\text { CRC } \\
\text { incidence }^{c}\end{array}$ & $\begin{array}{c}\text { CRC } \\
\text { mortality }^{c}\end{array}$ & \\
\hline $\begin{array}{l}\text { No screening } \\
\text { COL 50-55 y }\end{array}$ & 0 & 0 & 0 & 23 & 0 & 52 & 19 & 134 & 0 & $1,918,503$ & 0 & 0 & 0 & Dominated \\
\hline $3 y$ & 0 & 234 & 566 & 808 & 4 & 28 & 6 & 119 & 32 & $2,148,408$ & 229,905 & 47 & 70 & Dominated \\
\hline $5 y$ & 0 & 231 & 352 & 591 & 3 & 31 & 6 & 126 & 31 & $2,023,494$ & 104,991 & 41 & 66 & Dominated \\
\hline $10 y$ & 0 & 214 & 334 & 558 & 3 & 32 & 7 & 127 & 29 & $2,015,966$ & 97,463 & 38 & 62 & Efficient \\
\hline \multicolumn{15}{|l|}{ COL 50-60 y } \\
\hline $3 y$ & 0 & 242 & 575 & 825 & 4 & 27 & 6 & 119 & 33 & $2,155,878$ & 237,376 & 48 & 71 & Dominated \\
\hline $5 y$ & 0 & 234 & 354 & 597 & 3 & 31 & 6 & 126 & 31 & $2,025,210$ & 106,707 & 41 & 67 & Efficient \\
\hline $10 y$ & 0 & 225 & 345 & 579 & 3 & 31 & 7 & 127 & 30 & $2,021,207$ & 102,704 & 40 & 66 & Efficient \\
\hline \multicolumn{15}{|l|}{ COL 50-65 y } \\
\hline $3 y$ & 0 & 244 & 576 & 827 & 4 & 27 & 6 & 119 & 33 & $2,157,230$ & 238,727 & 48 & 71 & Dominated \\
\hline $5 \mathrm{y}$ & 0 & 235 & 354 & 598 & 3 & 31 & 6 & 126 & 31 & $2,025,651$ & 107,148 & 41 & 67 & Dominated \\
\hline $10 y$ & 0 & 225 & 345 & 579 & 3 & 31 & 7 & 127 & 30 & $2,021,207$ & 102,704 & 40 & 66 & Dominated \\
\hline \multicolumn{15}{|l|}{ COL 50-70 y } \\
\hline $3 y$ & 0 & 244 & 576 & 828 & 4 & 27 & 6 & 119 & 33 & $2,157,394$ & 238,892 & 48 & 71 & Dominated \\
\hline $5 \mathrm{y}$ & 0 & 235 & 354 & 598 & 3 & 31 & 6 & 126 & 31 & $2,025,716$ & 107,213 & 41 & 67 & Efficient \\
\hline $10 y$ & 0 & 226 & 346 & 580 & 3 & 31 & 6 & 127 & 30 & $2,021,651$ & 103,148 & 40 & 66 & Dominated \\
\hline \multicolumn{15}{|l|}{ COL 50-75 y } \\
\hline $3 y$ & 0 & 244 & 576 & 828 & 4 & 27 & 6 & 119 & 33 & $2,157,431$ & 238,928 & 48 & 71 & Dominated \\
\hline $5 \mathrm{y}$ & 0 & 235 & 354 & 598 & 3 & 31 & 6 & 126 & 31 & $2,025,729$ & 107,227 & 41 & 67 & Dominated \\
\hline $10 y$ & 0 & 226 & 346 & 580 & 3 & 31 & 6 & 127 & 30 & $2,021,651$ & 103,148 & 40 & 66 & Dominated \\
\hline \multicolumn{15}{|l|}{ COL 45-55 y } \\
\hline $3 y$ & 0 & 419 & 896 & 1320 & 4 & 23 & 4 & 105 & 41 & $2,475,197$ & 556,694 & 56 & 78 & Dominated \\
\hline $5 y$ & 0 & 390 & 528 & 925 & 3 & 28 & 5 & 117 & 38 & $2,219,433$ & 300,930 & 47 & 73 & Dominated \\
\hline $10 \mathrm{y}$ & 0 & 361 & 505 & 873 & 3 & 28 & 5 & 119 & 37 & $2,195,135$ & 276,632 & 46 & 72 & Dominated \\
\hline \multicolumn{15}{|l|}{ COL 45-60 y } \\
\hline $3 y$ & 0 & 424 & 901 & 1331 & 4 & 23 & 4 & 105 & 41 & $2,479,908$ & 561,406 & 56 & 79 & Dominated \\
\hline 5 y & 0 & 393 & 530 & 930 & 3 & 27 & 5 & 117 & 38 & $2,221,064$ & 302,561 & 48 & 74 & Dominated \\
\hline $10 y$ & 0 & 361 & 505 & 873 & 3 & 28 & 5 & 119 & 37 & $2,195,135$ & 276,632 & 46 & 72 & Dominated \\
\hline \multicolumn{15}{|l|}{ COL 45-65 y } \\
\hline $3 y$ & 0 & 425 & 902 & 1332 & 4 & 23 & 4 & 105 & 41 & $2,480,593$ & 562,090 & 56 & 79 & Dominated \\
\hline 5 y & 0 & 394 & 531 & 931 & 3 & 27 & 5 & 117 & 38 & $2,221,496$ & 302,994 & 48 & 74 & Dominated \\
\hline $10 y$ & 0 & 364 & 507 & 877 & 3 & 28 & 5 & 119 & 37 & $2,197,099$ & 278,597 & 46 & 73 & Dominated \\
\hline \multicolumn{15}{|l|}{ COL 45-70 y } \\
\hline $3 y$ & 0 & 426 & 902 & 1333 & 4 & 23 & 4 & 105 & 41 & $2,480,935$ & 562,432 & 57 & 79 & Dominated \\
\hline 5 y & 0 & 394 & 531 & 931 & 3 & 27 & 5 & 117 & 38 & $2,221,588$ & 303,085 & 48 & 74 & Dominated \\
\hline $10 y$ & 0 & 364 & 507 & 877 & 3 & 28 & 5 & 119 & 37 & $2,197,099$ & 278,597 & 46 & 73 & Dominated \\
\hline
\end{tabular}




\begin{tabular}{|c|c|c|c|c|c|c|c|c|c|c|c|c|c|c|}
\hline & \multicolumn{14}{|c|}{ Outcomes per 1000 non-transplant cystic fibrosis individuals free of diagnosed cancer at age 30 years in 2017 (3\% discounted) } \\
\hline & \multicolumn{2}{|c|}{ Screening tests } & \multirow[b]{2}{*}{$\begin{array}{l}\text { Surveillance } \\
\text { COLs }\end{array}$} & \multirow[b]{2}{*}{$\begin{array}{l}\text { Total } \\
\text { COLs }\end{array}$} & \multirow[b]{2}{*}{ Complications } & \multirow[b]{2}{*}{$\begin{array}{c}\text { CRC } \\
\text { cases }^{C}\end{array}$} & \multirow[b]{2}{*}{$\begin{array}{c}\text { CRC } \\
\text { death }^{a, c}\end{array}$} & \multirow[b]{2}{*}{$\begin{array}{l}\text { LY with } \\
\text { CRC }\end{array}$} & \multirow[b]{2}{*}{$\mathrm{LYG}^{b}$} & \multirow[b]{2}{*}{$\begin{array}{c}\text { Total costs } \\
\text { (\$) }\end{array}$} & \multirow[b]{2}{*}{$\begin{array}{l}\text { Net costs } \\
(\$)\end{array}$} & \multicolumn{2}{|c|}{ Reductions $^{b}(\%)$} & \multirow[b]{2}{*}{$\begin{array}{l}\text { Efficient } \\
\text { strategy }\end{array}$} \\
\hline & FIT & COLs & & & & & & & & & & $\begin{array}{c}\text { CRC } \\
\text { incidence }^{c}\end{array}$ & $\begin{array}{c}\text { CRC } \\
\text { mortality }\end{array}$ & \\
\hline \multicolumn{15}{|c|}{ COL 45-75 y } \\
\hline $3 y$ & 0 & 426 & 902 & 1333 & 4 & 23 & 4 & 105 & 41 & $2,480,965$ & 562,462 & 57 & 79 & Dominated \\
\hline 5 y & 0 & 394 & 531 & 931 & 3 & 27 & 5 & 117 & 38 & $2,221,593$ & 303,090 & 48 & 74 & Efficient \\
\hline 10 y & 0 & 364 & 507 & 877 & 3 & 28 & 5 & 119 & 37 & $2,197,180$ & 278,677 & 46 & 73 & Dominated \\
\hline \multicolumn{15}{|c|}{ COL 40-55 y } \\
\hline $3 y$ & 0 & 788 & 1297 & 2088 & 5 & 20 & 3 & 93 & 48 & $3,073,485$ & $1,154,982$ & 62 & 84 & Dominated \\
\hline $5 y$ & 0 & 685 & 721 & 1411 & 4 & 25 & 4 & 109 & 44 & $2,589,046$ & 670,543 & 52 & 78 & Dominated \\
\hline $10 y$ & 0 & 584 & 654 & 1243 & 4 & 27 & 5 & 113 & 41 & $2,486,943$ & 568,440 & 48 & 73 & Dominated \\
\hline \multicolumn{15}{|c|}{ COL 40-60 y } \\
\hline 3 y & 0 & 791 & 1300 & 2094 & 5 & 20 & 3 & 93 & 48 & $3,075,938$ & $1,157,436$ & 63 & 84 & Dominated \\
\hline 5 y & 0 & 688 & 723 & 1416 & 4 & 25 & 4 & 109 & 44 & $2,590,515$ & 672,012 & 52 & 79 & Dominated \\
\hline $10 y$ & 0 & 592 & 663 & 1261 & 4 & 27 & 5 & 114 & 42 & $2,491,257$ & 572,754 & 49 & 76 & Dominated \\
\hline \multicolumn{15}{|c|}{ COL 40-65 y } \\
\hline $3 y$ & 0 & 793 & 1301 & 2097 & 5 & 20 & 3 & 93 & 48 & $3,077,629$ & $1,159,127$ & 63 & 84 & Dominated \\
\hline 5 y & 0 & 689 & 724 & 1417 & 4 & 25 & 4 & 109 & 44 & $2,590,952$ & 672,449 & 52 & 79 & Dominated \\
\hline $10 y$ & 0 & 592 & 663 & 1261 & 4 & 27 & 5 & 114 & 42 & $2,491,257$ & 572,754 & 49 & 76 & Dominated \\
\hline \multicolumn{15}{|c|}{ COL 40-70 y } \\
\hline 3 y & 0 & 793 & 1301 & 2097 & 5 & 20 & 3 & 93 & 48 & $3,077,867$ & $1,159,364$ & 63 & 84 & Dominated \\
\hline $5 y$ & 0 & 689 & 724 & 1417 & 4 & 25 & 4 & 109 & 44 & $2,591,030$ & 672,527 & 52 & 79 & Efficient \\
\hline $10 \mathrm{y}$ & 0 & 593 & 663 & 1261 & 4 & 27 & 4 & 114 & 42 & $2,491,646$ & 573,143 & 49 & 77 & Dominated \\
\hline \multicolumn{15}{|c|}{ COL 40-75 y } \\
\hline 3 y & 0 & 793 & 1301 & 2097 & 5 & 20 & 3 & 93 & 48 & $3,077,874$ & $1,159,371$ & 63 & 84 & Efficient \\
\hline $5 y$ & 0 & 689 & 724 & 1417 & 4 & 25 & 4 & 109 & 44 & $2,591,048$ & 672,546 & 52 & 79 & Optimal \\
\hline $10 y$ & 0 & 593 & 663 & 1261 & 4 & 27 & 4 & 114 & 42 & $2,491,646$ & 573,143 & 49 & 77 & Dominated \\
\hline \multicolumn{15}{|c|}{ COL 35-55 y } \\
\hline 3 y & 0 & 1473 & 1691 & 3167 & 5 & 18 & 2 & 85 & 53 & $3,992,038$ & $2,073,535$ & 66 & 87 & Dominated \\
\hline $5 y$ & 0 & 1194 & 907 & 2105 & 4 & 24 & 4 & 104 & 48 & $3,174,604$ & $1,256,101$ & 54 & 81 & Dominated \\
\hline $10 \mathrm{y}$ & 0 & 939 & 802 & 1745 & 4 & 26 & 4 & 110 & 45 & $2,900,743$ & 982,240 & 51 & 78 & Dominated \\
\hline \multicolumn{15}{|c|}{ COL 35-60 y } \\
\hline 3 y & 0 & 1481 & 1699 & 3182 & 5 & 18 & 2 & 84 & 53 & 3,998,695 & $2,080,192$ & 66 & 88 & Dominated \\
\hline 5 y & 0 & 1197 & 909 & 2110 & 4 & 24 & 4 & 104 & 48 & $3,175,886$ & $1,257,384$ & 55 & 81 & Dominated \\
\hline $10 y$ & 0 & 939 & 802 & 1745 & 4 & 26 & 4 & 110 & 45 & $2,900,743$ & 982,240 & 51 & 78 & Dominated \\
\hline COL 35 & & & & & & & & & & & & & & \\
\hline 3 y & 0 & 1482 & 1700 & 3185 & 5 & 18 & 2 & 84 & 53 & $4,000,132$ & $2,081,629$ & 67 & 88 & Dominated \\
\hline $5 y$ & 0 & 1198 & 909 & 2111 & 4 & 24 & 4 & 104 & 48 & $3,176,328$ & $1,257,825$ & 55 & 82 & Dominated \\
\hline $\begin{array}{c}10 y \\
\operatorname{coL} 35\end{array}$ & 0 & 941 & 803 & 1749 & 4 & 25 & 4 & 110 & 45 & $2,902,724$ & 984,222 & 51 & 79 & Dominated \\
\hline $\begin{array}{c}\text { COL 35 } \\
3 y\end{array}$ & 0 & 1482 & 1700 & 3185 & 5 & & & & & $4,000,269$ & 2.081 .766 & & & \\
\hline $\begin{array}{l}3 \mathrm{y} \\
5 \mathrm{y}\end{array}$ & 0 & 1198 & 909 & 2111 & 4 & 24 & 4 & $\begin{array}{r}84 \\
104\end{array}$ & $\begin{array}{l}53 \\
48\end{array}$ & $\begin{array}{l}4,000,209 \\
3,176,413\end{array}$ & $\begin{array}{l}2,001, / 00 \\
1,257,910\end{array}$ & $\begin{array}{l}67 \\
55\end{array}$ & $\begin{array}{l}88 \\
82\end{array}$ & $\begin{array}{l}\text { Dominated } \\
\text { Dominated }\end{array}$ \\
\hline $10 y$ & 0 & 941 & 803 & 1749 & 4 & 25 & 4 & 110 & 45 & $2,902,724$ & 984,222 & 51 & 79 & Dominated \\
\hline
\end{tabular}


Outcomes per 1000 non-transplant cystic fibrosis individuals free of diagnosed cancer at age 30 years in 2017 (3\% discounted)

Screening tests

\begin{tabular}{|c|c|c|c|c|c|c|c|}
\hline \multirow[b]{2}{*}{$\begin{array}{c}\text { CRC } \\
\text { death }^{a, c}\end{array}$} & \multirow[b]{2}{*}{$\begin{array}{l}\text { LY with } \\
\text { CRC }\end{array}$} & \multirow[b]{2}{*}{$\mathrm{LYG}^{b}$} & \multirow[b]{2}{*}{$\begin{array}{l}\text { Total costs } \\
\text { (\$) }\end{array}$} & \multirow[b]{2}{*}{$\begin{array}{l}\text { Net costs } \\
\text { (\$) }\end{array}$} & \multicolumn{2}{|c|}{ Reductions $^{b}(\%)$} & \multirow[b]{2}{*}{$\begin{array}{l}\text { Efficient } \\
\text { strategy }\end{array}$} \\
\hline & & & & & $\begin{array}{c}\text { CRC } \\
\text { incidence }^{c}\end{array}$ & $\begin{array}{c}\text { CRC } \\
\text { mortality }^{c}\end{array}$ & \\
\hline
\end{tabular}

COL 35-75 y

3 y
5 y
10 y
COL $30-55$ y

COL 30-55 y

$3 \mathrm{y}$

$5 \mathrm{y}$
$10 \mathrm{y}$

$10 y$
COL 30-60 y

$3 \mathrm{y}$
$5 \mathrm{y}$

$10 \mathrm{y}$

COL 30-65 y

$3 \mathrm{y}$
$5 \mathrm{y}$
$10 \mathrm{y}$

COL 30-70 y

$3 \mathrm{y}$
$5 \mathrm{y}$
$10 \mathrm{y}$

$10 y$
$\operatorname{coL} 30-75 y$

$3 y$
$5 y$
$10 y$

FIT COLs

$\begin{array}{cc}\begin{array}{c}\text { Surveillance } \\ \text { COLs }\end{array} & \text { Total } \\ \text { COLs }\end{array}$

OLs Complications

cases $^{c}$ death $^{a, c}$

CRC

$0 \quad 1482 \quad 1700$

$\begin{array}{ll}1700 & 3185\end{array}$

$\begin{array}{rrrr}0 & 1198 & 909 & 2111 \\ 0 & 942 & 803 & 1749\end{array}$

$\begin{array}{llll}0 & 2664 & 2056 & 4722 \\ 0 & 2019 & 1081\end{array}$

$\begin{array}{rrrr}0 & 2019 & 1081 & 3103 \\ 0 & 1469 & 930 & 2404\end{array}$

$\begin{array}{llll}0 & 2670 & 2061 & 4733\end{array}$

$\begin{array}{llll}0 & 2022 & 1083 & 3108\end{array}$

$0 \quad 1478$

939

2421

$2670 \quad 2062 \quad 4734$

$\begin{array}{rrrr}0 & 2022 & 1084 & 3109 \\ 0 & 1478 & 939 & 2421\end{array}$

$\begin{array}{llll}0 & 2671 & 2062 & 4734\end{array}$

$0 \quad 2022 \quad 1084 \quad 3109$

$\begin{array}{rrrr} & 1479 & 939 & 2422 \\ 0 & 2671 & 2062 & 4734\end{array}$

$\begin{array}{rrrr}0 & 2022 & 1084 & 3109 \\ 0 & 1479 & 939 & 2422\end{array}$

COL, colonoscopy; CRC, colorectal cancer; LY, life-years; LYG, LY gained compared with no screening; Grey row indicates optimal screening strategy.

Including deaths from complications of screening.

${ }^{b}$ Compared with no screening.

${ }^{c} \mathrm{CRC}$ cases and CRC death were not discounted. 
Outcomes per 1,000 non-transplant cystic fibrosis individuals free of diagnosed cancer at age 30 years in 2017 (3\% discounted)

\begin{tabular}{|c|c|c|c|c|c|c|c|c|c|c|c|c|c|c|}
\hline & \multicolumn{2}{|c|}{ Screening tests } & \multirow[b]{2}{*}{$\begin{array}{c}\text { Surveillance } \\
\text { COLs }\end{array}$} & \multirow[b]{2}{*}{$\begin{array}{l}\text { Total } \\
\text { COLs }\end{array}$} & \multirow[b]{2}{*}{ Complications } & \multirow[b]{2}{*}{$\begin{array}{c}\text { CRC } \\
\text { cases }^{c}\end{array}$} & \multirow[b]{2}{*}{$\begin{array}{c}\text { CRC } \\
\text { death }^{a, c}\end{array}$} & \multirow[b]{2}{*}{$\begin{array}{l}\text { LY with } \\
\text { CRC }\end{array}$} & \multirow[b]{2}{*}{$\mathrm{LYG}^{b}$} & \multirow[b]{2}{*}{$\begin{array}{c}\text { Total costs } \\
(\$)\end{array}$} & \multirow[b]{2}{*}{$\begin{array}{l}\text { Net costs } \\
(\$)\end{array}$} & \multicolumn{2}{|c|}{ Reductions $^{b}(\%)$} & \multirow[b]{2}{*}{$\begin{array}{l}\text { Efficient } \\
\text { strategy }\end{array}$} \\
\hline & FIT & COLs & & & & & & & & & & $\begin{array}{c}\text { CRC } \\
\text { incidence }^{c}\end{array}$ & $\begin{array}{c}\text { CRC } \\
\text { mortality }^{c}\end{array}$ & \\
\hline No screening & 0 & 23 & 0 & 23 & 0 & 52 & 19 & 134 & 0 & $1,918,503$ & 0 & 0 & 0 & Dominated \\
\hline FIT 50-55 y & 864 & 0 & 120 & 210 & 1 & 45 & 12 & 153 & 19 & $2,038,443$ & 119,940 & 13 & 37 & Dominated \\
\hline FIT 50-60 y & 1164 & 0 & 148 & 255 & 1 & 43 & 9 & 158 & 25 & $2,052,169$ & 133,666 & 18 & 50 & Dominated \\
\hline FIT 50-65 y & 1300 & 0 & 158 & 273 & 2 & 42 & 8 & 161 & 27 & $2,063,754$ & 145,251 & 20 & 58 & Dominated \\
\hline FIT 50-70 y & 1353 & 0 & 161 & 279 & 2 & 42 & 7 & 163 & 28 & $2,072,133$ & 153,630 & 20 & 61 & Dominated \\
\hline FIT $50-75$ y & 1369 & 0 & 162 & 281 & 2 & 42 & 7 & 163 & 28 & $2,074,725$ & 156,222 & 20 & 62 & Dominated \\
\hline FIT $45-55$ y & 1959 & 0 & 194 & 329 & 2 & 42 & 10 & 155 & 28 & $2,115,102$ & 196,599 & 19 & 48 & Dominated \\
\hline FIT $45-60 y$ & 2228 & 0 & 216 & 366 & 2 & 40 & 8 & 159 & 32 & $2,126,869$ & 208,366 & 23 & 59 & Dominated \\
\hline FIT 45-65 y & 2352 & 0 & 226 & 382 & 2 & 40 & 7 & 162 & 34 & $2,137,804$ & 219,302 & 25 & 65 & Dominated \\
\hline FIT $45-70 y$ & 2400 & 0 & 228 & 388 & 2 & 39 & 6 & 163 & 35 & $2,145,442$ & 226,939 & 25 & 69 & Dominated \\
\hline FIT $45-75 y$ & 2416 & 0 & 229 & 389 & 2 & 39 & 6 & 164 & 35 & $2,148,080$ & 229,577 & 25 & 70 & Dominated \\
\hline FIT $40-55$ y & 3696 & 0 & 268 & 463 & 2 & 40 & 9 & 155 & 34 & $2,252,661$ & 334,158 & 23 & 54 & Dominated \\
\hline FIT 40-60 y & 3948 & 0 & 288 & 497 & 2 & 39 & 7 & 159 & 38 & $2,266,287$ & 347,784 & 27 & 64 & Dominated \\
\hline FIT 40-65 y & 4064 & 0 & 296 & 512 & 2 & 38 & 6 & 162 & 40 & $2,276,322$ & 357,819 & 28 & 70 & Dominated \\
\hline FIT $40-70 y$ & 4110 & 0 & 299 & 517 & 2 & 38 & 5 & 163 & 41 & $2,283,302$ & 364,799 & 28 & 73 & Dominated \\
\hline FIT $40-75$ y & 4125 & 0 & 300 & 519 & 2 & 38 & 5 & 164 & 41 & $2,286,016$ & 367,513 & 28 & 75 & Efficient \\
\hline FIT 35-55 y & 6360 & 0 & 336 & 622 & 2 & 39 & 8 & 155 & 39 & $2,469,942$ & 551,440 & 26 & 58 & Dominated \\
\hline FIT $35-60 y$ & 6602 & 0 & 356 & 654 & 2 & 37 & 6 & 159 & 43 & $2,482,622$ & 564,119 & 29 & 68 & Dominated \\
\hline FIT 35-65 y & 6714 & 0 & 364 & 668 & 2 & 36 & 5 & 162 & 45 & $2,492,455$ & 573,952 & 30 & 74 & Dominated \\
\hline FIT $35-70 y$ & 6758 & 0 & 366 & 674 & 2 & 36 & 4 & 163 & 45 & $2,498,628$ & 580,125 & 31 & 77 & Dominated \\
\hline FIT 35-75 y & 6772 & 0 & 367 & 675 & 2 & 36 & 4 & 163 & 46 & $2,501,004$ & 582,501 & 31 & 78 & Optimal \\
\hline FIT $30-55$ y & 10,379 & 0 & 397 & 821 & 2 & 38 & 8 & 155 & 42 & $2,800,037$ & 881,534 & 27 & 61 & Dominated \\
\hline FIT $30-60 y$ & 10,616 & 0 & 416 & 852 & 2 & 36 & 6 & 159 & 46 & $2,812,063$ & 893,560 & 30 & 70 & Dominated \\
\hline FIT 30-65 y & 10,726 & 0 & 424 & 866 & 2 & 36 & 5 & 161 & 48 & $2,821,545$ & 903,042 & 32 & 76 & Dominated \\
\hline FIT $30-70 y$ & 10,769 & 0 & 427 & 871 & 2 & 36 & 4 & 162 & 49 & $2,828,060$ & 909,557 & 32 & 78 & Dominated \\
\hline FIT $30-75$ y & 10,783 & 0 & 427 & 872 & 2 & 36 & 4 & 163 & 49 & $2,830,319$ & 911,816 & 32 & 80 & Efficient \\
\hline
\end{tabular}

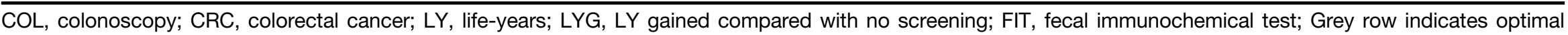
screening strategy.

${ }^{a}$ Including deaths from complications of screening.

${ }^{b}$ Compared with no screening.

${ }^{c} \mathrm{CRC}$ cases and CRC death were not discounted. 
Outcomes per 1,000 transplant cystic fibrosis individuals free of diagnosed cancer at age 30 years in 2017 (with organ transplant

at age $30,3 \%$ discounted)

\begin{tabular}{|c|c|c|c|c|c|c|c|c|c|c|c|c|c|c|}
\hline & \multicolumn{2}{|c|}{ Screening tests } & \multirow[b]{2}{*}{$\begin{array}{l}\text { Surveillance } \\
\text { COLs }\end{array}$} & \multirow[b]{2}{*}{$\begin{array}{l}\text { Total } \\
\text { COLs }\end{array}$} & \multirow[b]{2}{*}{ Complications } & \multirow[b]{2}{*}{$\begin{array}{c}\text { CRC } \\
\text { cases }^{c}\end{array}$} & \multirow[b]{2}{*}{$\begin{array}{c}\text { CRC } \\
\text { death }^{a, c}\end{array}$} & \multirow[b]{2}{*}{$\begin{array}{l}\text { LY with } \\
\text { CRC }\end{array}$} & \multirow[b]{2}{*}{$\mathrm{LYG}^{b}$} & \multirow[b]{2}{*}{$\begin{array}{c}\text { Total costs } \\
\text { (\$) }\end{array}$} & \multirow[b]{2}{*}{$\begin{array}{l}\text { Net costs } \\
\text { (\$) }\end{array}$} & \multicolumn{2}{|c|}{ Reductions $^{b}(\%)$} & \multirow[b]{2}{*}{$\begin{array}{l}\text { Efficient } \\
\text { strategy }\end{array}$} \\
\hline & FIT & COLs & & & & & & & & & & $\begin{array}{c}\text { CRC } \\
\text { incidence }^{c}\end{array}$ & $\begin{array}{c}\text { CRC } \\
\text { mortality }^{C}\end{array}$ & \\
\hline \multicolumn{14}{|l|}{ COL 50-55 y } & Dominated \\
\hline $3 y$ & 0 & 125 & 173 & 314 & 2 & 48 & 13 & 143 & 15 & $2,437,339$ & 372,685 & 8 & 40 & Dominated \\
\hline $5 y$ & 0 & 125 & 152 & 293 & 1 & 48 & 14 & 143 & 14 & $2,420,864$ & 356,209 & 8 & 39 & Dominated \\
\hline \multicolumn{14}{|l|}{ COL 50-60 y } & Dominated \\
\hline $3 y$ & 0 & 125 & 173 & 314 & 2 & 48 & 13 & 143 & 15 & $2,437,341$ & 372,687 & 8 & 40 & Dominated \\
\hline $5 y$ & 0 & 125 & 152 & 293 & 1 & 48 & 14 & 143 & 14 & $2,420,865$ & 356,211 & 8 & 39 & Dominated \\
\hline $\begin{array}{c}10 y \\
\text { COL 50-65 y }\end{array}$ & 0 & 124 & 151 & 293 & 1 & 48 & 14 & 143 & 14 & $2,420,644$ & 355,990 & 8 & 39 & Dominated \\
\hline $3 y$ & 0 & 125 & 173 & 314 & 2 & 48 & 13 & 143 & 15 & $2,437,341$ & 372,687 & 8 & 40 & Dominated \\
\hline $5 y$ & 0 & 125 & 152 & 293 & 1 & 48 & 14 & 143 & 14 & $2,420,865$ & 356,211 & 8 & 39 & Dominated \\
\hline \multicolumn{14}{|l|}{ COL 50-70 y } & Dominated \\
\hline $3 y$ & 0 & 125 & 173 & 314 & 2 & 48 & 13 & 143 & 15 & $2,437,341$ & 372,687 & 8 & 40 & Dominated \\
\hline $5 y$ & 0 & 125 & 152 & 293 & 1 & 48 & 14 & 143 & 14 & $2,420,865$ & 356,211 & 8 & 39 & Dominated \\
\hline $\begin{array}{c}10 y \\
\text { COL 50-75 y }\end{array}$ & 0 & 124 & 151 & 293 & 1 & 48 & 14 & 143 & 14 & $2,420,644$ & 355,990 & 8 & 39 & Dominated \\
\hline $3 y$ & 0 & 125 & 173 & 314 & 2 & 48 & 13 & 143 & 15 & $2,437,341$ & 372,687 & 8 & 40 & Dominated \\
\hline $5 y$ & 0 & 125 & 152 & 293 & 1 & 48 & 14 & 143 & 14 & $2,420,865$ & 356,211 & 8 & 39 & Dominated \\
\hline $10 y$ & 0 & 124 & 151 & 293 & 1 & 48 & 14 & 143 & 14 & $2,420,644$ & 355,990 & 8 & 39 & Dominated \\
\hline \multicolumn{15}{|l|}{ COL 45-55 y } \\
\hline $3 y$ & 0 & 200 & 416 & 628 & 3 & 38 & 9 & 137 & 29 & $2,481,276$ & 416,622 & 27 & 59 & Dominated \\
\hline $5 y$ & 0 & 200 & 343 & 554 & 2 & 39 & 9 & 139 & 28 & $2,438,899$ & 374,244 & 25 & 58 & Efficient \\
\hline 10 y & 0 & 199 & 342 & 553 & 2 & 39 & 9 & 139 & 28 & $2,438,362$ & 373,707 & 25 & 57 & Efficient \\
\hline \multicolumn{15}{|l|}{ COL 45-60 y } \\
\hline $3 y$ & 0 & 200 & 416 & 628 & 3 & 38 & 9 & 137 & 29 & $2,481,280$ & 416,625 & 27 & 59 & Dominated \\
\hline $5 y$ & 0 & 200 & 343 & 554 & 2 & 39 & 9 & 139 & 28 & $2,438,902$ & 374,247 & 25 & 58 & Dominated \\
\hline 10 y & 0 & 199 & 342 & 553 & 2 & 39 & 9 & 139 & 28 & $2,438,362$ & 373,707 & 25 & 57 & Dominated \\
\hline \multicolumn{15}{|l|}{ COL 45-65 y } \\
\hline $3 y$ & 0 & 200 & 416 & 628 & 3 & 38 & 9 & 137 & 29 & $2,481,280$ & 416,625 & 27 & 59 & Dominated \\
\hline 5 y & 0 & 200 & 343 & 554 & 2 & 39 & 9 & 139 & 28 & $2,438,902$ & 374,247 & 25 & 58 & Dominated \\
\hline 10 y & 0 & 199 & 342 & 553 & 2 & 39 & 9 & 139 & 28 & $2,438,362$ & 373,707 & 25 & 57 & Dominated \\
\hline \multicolumn{15}{|l|}{ COL 45-70 y } \\
\hline $3 y$ & 0 & 200 & 416 & 628 & 3 & 38 & 9 & 137 & 29 & $2,481,280$ & 416,625 & 27 & 59 & Dominated \\
\hline $5 \mathrm{y}$ & 0 & 200 & 343 & 554 & 2 & 39 & 9 & 139 & 28 & $2,438,902$ & 374,247 & 25 & 58 & Dominated \\
\hline $10 y$ & 0 & 199 & 342 & 553 & 2 & 39 & 9 & 139 & 28 & $2,438,362$ & 373,707 & 25 & 57 & Dominated \\
\hline
\end{tabular}


Outcomes per 1,000 transplant cystic fibrosis individuals free of diagnosed cancer at age 30 years in 2017 (with organ transplant at age $30,3 \%$ discounted)

\begin{tabular}{|c|c|c|c|c|c|c|c|c|c|c|c|c|c|c|}
\hline & \multicolumn{2}{|c|}{ Screening tests } & \multirow[b]{2}{*}{$\begin{array}{c}\text { Surveillance } \\
\text { COLs }\end{array}$} & \multirow[b]{2}{*}{$\begin{array}{l}\text { Total } \\
\text { COLs }\end{array}$} & \multirow[b]{2}{*}{ Complications } & \multirow[b]{2}{*}{$\begin{array}{c}\text { CRC } \\
\text { cases }^{c}\end{array}$} & \multirow[b]{2}{*}{$\begin{array}{c}\text { CRC } \\
\text { death }^{a, c}\end{array}$} & \multirow[b]{2}{*}{$\begin{array}{l}\text { LY with } \\
\text { CRC }\end{array}$} & \multirow[b]{2}{*}{ LYG $^{b}$} & \multirow[b]{2}{*}{$\begin{array}{c}\text { Total costs } \\
(\$)\end{array}$} & \multirow[b]{2}{*}{$\begin{array}{l}\text { Net costs } \\
(\$)\end{array}$} & \multicolumn{2}{|c|}{ Reductions $^{b}(\%)$} & \multirow[b]{2}{*}{$\begin{array}{l}\text { Efficient } \\
\text { strategy }\end{array}$} \\
\hline & FIT & COLs & & & & & & & & & & $\begin{array}{c}\text { CRC } \\
\text { incidence }^{c}\end{array}$ & $\begin{array}{c}\text { CRC } \\
\text { mortality }^{C}\end{array}$ & \\
\hline \multicolumn{15}{|c|}{ COL 45-75 y } \\
\hline $3 y$ & 0 & 200 & 416 & 628 & 3 & 38 & 9 & 137 & 29 & $2,481,280$ & 416,625 & 27 & 59 & Dominated \\
\hline $5 y$ & 0 & 200 & 343 & 554 & 2 & 39 & 9 & 139 & 28 & $2,438,902$ & 374,247 & 25 & 58 & Dominated \\
\hline $10 y$ & 0 & 199 & 342 & 553 & 2 & 39 & 9 & 139 & 28 & $2,438,362$ & 373,707 & 25 & 57 & Dominated \\
\hline \multicolumn{15}{|c|}{ COL 40-55 y } \\
\hline $3 y$ & 0 & 328 & 774 & 1109 & 3 & 30 & 6 & 123 & 44 & $2,707,578$ & 642,923 & 42 & 74 & Dominated \\
\hline $5 y$ & 0 & 324 & 591 & 923 & 3 & 34 & 7 & 129 & 42 & $2,600,975$ & 536,321 & 36 & 70 & Efficient \\
\hline $10 y$ & 0 & 320 & 582 & 909 & 3 & 34 & 7 & 129 & 42 & $2,597,514$ & 532,860 & 35 & 70 & Dominated \\
\hline \multicolumn{15}{|c|}{ COL 40-60 y } \\
\hline $3 y$ & 0 & 328 & 774 & 1109 & 3 & 30 & 6 & 123 & 44 & $2,707,578$ & 642,924 & 42 & 74 & Dominated \\
\hline $5 y$ & 0 & 324 & 591 & 923 & 3 & 34 & 7 & 129 & 42 & $2,600,975$ & 536,321 & 36 & 70 & Dominated \\
\hline $10 y$ & 0 & 320 & 582 & 909 & 3 & 34 & 7 & 129 & 42 & $2,597,584$ & 532,929 & 35 & 70 & Dominated \\
\hline \multicolumn{15}{|c|}{ COL 40-65 y } \\
\hline $3 y$ & 0 & 328 & 774 & 1109 & 3 & 30 & 6 & 123 & 44 & $2,707,578$ & 642,924 & 42 & 74 & Dominated \\
\hline $5 y$ & 0 & 324 & 591 & 923 & 3 & 34 & 7 & 129 & 42 & $2,600,975$ & 536,321 & 36 & 70 & Dominated \\
\hline $10 y$ & 0 & 320 & 582 & 909 & 3 & 34 & 7 & 129 & 42 & $2,597,584$ & 532,929 & 35 & 70 & Dominated \\
\hline \multicolumn{15}{|c|}{ COL 40-70 y } \\
\hline $3 y$ & 0 & 328 & 774 & 1109 & 3 & 30 & 6 & 123 & 44 & $2,707,578$ & 642,924 & 42 & 74 & Dominated \\
\hline $5 y$ & 0 & 324 & 591 & 923 & 3 & 34 & 7 & 129 & 42 & $2,600,975$ & 536,321 & 36 & 70 & Dominated \\
\hline $10 y$ & 0 & 320 & 582 & 909 & 3 & 34 & 7 & 129 & 42 & $2,597,584$ & 532,929 & 35 & 70 & Dominated \\
\hline \multicolumn{15}{|c|}{ COL 40-75 y } \\
\hline $3 y$ & 0 & 328 & 774 & 1109 & 3 & 30 & 6 & 123 & 44 & $2,707,578$ & 642,924 & 42 & 74 & Dominated \\
\hline $5 \mathrm{y}$ & 0 & 324 & 591 & 923 & 3 & 34 & 7 & 129 & 42 & $2,600,975$ & 536,321 & 36 & 70 & Dominated \\
\hline $10 y$ & 0 & 320 & 582 & 909 & 3 & 34 & 7 & 129 & 42 & $2,597,584$ & 532,929 & 35 & 70 & Dominated \\
\hline \multicolumn{15}{|c|}{ COL 35-55 y } \\
\hline $3 y$ & 0 & 642 & 1265 & 1912 & 4 & 26 & 4 & 110 & 56 & $3,346,546$ & 1,281,892 & 49 & 82 & Optimal \\
\hline $5 y$ & 0 & 607 & 838 & 1451 & 3 & 31 & 5 & 122 & 52 & $3,028,100$ & 963,446 & 41 & 77 & Efficient \\
\hline $10 y$ & 0 & 571 & 788 & 1364 & 3 & 32 & 6 & 125 & 49 & $2,980,739$ & 916,084 & 39 & 75 & Dominated \\
\hline \multicolumn{15}{|c|}{ COL 35-60 y } \\
\hline $3 y$ & 0 & 642 & 1265 & 1912 & 4 & 26 & 4 & 110 & 56 & $3,346,548$ & $1,281,894$ & 49 & 82 & Dominated \\
\hline $5 y$ & 0 & 607 & 838 & 1451 & 3 & 31 & 5 & 122 & 52 & $3,028,100$ & 963,446 & 41 & 77 & Dominated \\
\hline $10 y$ & 0 & 571 & 788 & 1364 & 3 & 32 & 6 & 125 & 49 & $2,980,739$ & 916,084 & 39 & 75 & Dominated \\
\hline \multicolumn{15}{|c|}{ COL 35-65 y } \\
\hline $3 y$ & 0 & 642 & 1265 & 1912 & 4 & 26 & 4 & 110 & 56 & $3,346,548$ & $1,281,894$ & 49 & 82 & Dominated \\
\hline $5 y$ & 0 & 607 & 838 & 1451 & 3 & 31 & 5 & 122 & 52 & $3,028,100$ & 963,446 & 41 & 77 & Dominated \\
\hline $10 y$ & 0 & 571 & 788 & 1364 & 3 & 32 & 6 & 125 & 49 & $2,980,739$ & 916,084 & 39 & 75 & Dominated \\
\hline
\end{tabular}


Outcomes per 1,000 transplant cystic fibrosis individuals free of diagnosed cancer at age 30 years in 2017 (with organ transplant at age $30,3 \%$ discounted)

\begin{tabular}{|c|c|c|c|c|c|c|c|c|c|c|c|c|c|c|}
\hline & \multicolumn{2}{|c|}{ Screening tests } & \multirow[b]{2}{*}{$\begin{array}{c}\text { Surveillance } \\
\text { COLs }\end{array}$} & \multirow[b]{2}{*}{$\begin{array}{l}\text { Total } \\
\text { COLs }\end{array}$} & \multirow[b]{2}{*}{ Complications } & \multirow[b]{2}{*}{$\begin{array}{c}\text { CRC } \\
\text { cases }^{C}\end{array}$} & \multirow[b]{2}{*}{$\begin{array}{c}\text { CRC } \\
\text { death }^{a, c}\end{array}$} & \multirow[b]{2}{*}{$\begin{array}{l}\text { LY with } \\
\text { CRC }\end{array}$} & \multirow[b]{2}{*}{$\mathrm{LYG}^{b}$} & \multirow[b]{2}{*}{$\begin{array}{c}\text { Total costs } \\
\text { (\$) }\end{array}$} & \multirow[b]{2}{*}{$\begin{array}{l}\text { Net costs } \\
\text { (\$) }\end{array}$} & \multicolumn{2}{|c|}{ Reductions $^{b}(\%)$} & \multirow[b]{2}{*}{$\begin{array}{l}\text { Efficient } \\
\text { strategy }\end{array}$} \\
\hline & FIT & COLs & & & & & & & & & & $\begin{array}{c}\text { CRC } \\
\text { incidence }^{c}\end{array}$ & $\begin{array}{c}\text { CRC } \\
\text { mortality }^{c}\end{array}$ & \\
\hline \multicolumn{15}{|c|}{ COL 35-70 y } \\
\hline 3 y & 0 & 642 & 1265 & 1912 & 4 & 26 & 4 & 110 & 56 & $3,346,548$ & $1,281,894$ & 49 & 82 & Dominated \\
\hline $5 y$ & 0 & 607 & 838 & 1451 & 3 & 31 & 5 & 122 & 52 & $3,028,100$ & 963,446 & 41 & 77 & Dominated \\
\hline $10 y$ & 0 & 571 & 788 & 1364 & 3 & 32 & 6 & 125 & 49 & $2,980,739$ & 916,084 & 39 & 75 & Dominated \\
\hline \multicolumn{15}{|c|}{ COL 35-75 y } \\
\hline 3 y & 0 & 642 & 1265 & 1912 & 4 & 26 & 4 & 110 & 56 & $3,346,548$ & $1,281,894$ & 49 & 82 & Dominated \\
\hline $5 y$ & 0 & 607 & 838 & 1451 & 3 & 31 & 5 & 122 & 52 & $3,028,100$ & 963,446 & 41 & 77 & Dominated \\
\hline $10 y$ & 0 & 571 & 788 & 1364 & 3 & 32 & 6 & 125 & 49 & $2,980,739$ & 916,084 & 39 & 75 & Dominated \\
\hline \multicolumn{15}{|c|}{ COL 30-55 y } \\
\hline 3 y & 0 & 1511 & 1826 & 3340 & 5 & 25 & 3 & 99 & 64 & $4,622,190$ & $2,557,535$ & 53 & 87 & Efficient \\
\hline $5 y$ & 0 & 1316 & 1080 & 2400 & 4 & 29 & 4 & 117 & 57 & $3,888,961$ & $1,824,306$ & 43 & 80 & Dominated \\
\hline \multirow{2}{*}{\multicolumn{15}{|c|}{ COL 30-60 y }} \\
\hline & & & & & & & & & & & & & & \\
\hline 3 y & 0 & 1511 & 1826 & 3340 & 5 & 25 & 3 & 99 & 64 & $4,622,193$ & $2,557,539$ & 53 & 87 & Dominated \\
\hline $5 \mathrm{y}$ & 0 & 1316 & 1080 & 2400 & 4 & 29 & 4 & 117 & 57 & $3,888,964$ & $1,824,309$ & 43 & 80 & Dominated \\
\hline \multirow{2}{*}{\multicolumn{15}{|c|}{ COL 30-65 y }} \\
\hline & & & & & & & & & & & & & & \\
\hline $3 y$ & 0 & 1511 & 1826 & 3340 & 5 & 25 & 3 & 99 & 64 & $4,622,193$ & $2,557,539$ & 53 & 87 & Dominated \\
\hline $5 y$ & 0 & 1316 & 1080 & 2400 & 4 & 29 & 4 & 117 & 57 & $3,888,964$ & $1,824,309$ & 43 & 80 & Dominated \\
\hline $10 y$ & 0 & 1134 & 971 & 2110 & 4 & 31 & 5 & 121 & 54 & $3,656,827$ & $1,592,172$ & 41 & 78 & Dominated \\
\hline \multicolumn{15}{|c|}{ COL 30-70 y } \\
\hline $3 y$ & 0 & 1511 & 1826 & 3340 & 5 & 25 & 3 & 99 & 64 & $4,622,193$ & $2,557,539$ & 53 & 87 & Dominated \\
\hline $5 y$ & 0 & 1316 & 1080 & 2400 & 4 & 29 & 4 & 117 & 57 & $3,888,964$ & $1,824,309$ & 43 & 80 & Dominated \\
\hline \multicolumn{15}{|c|}{ COL 30-75 y } \\
\hline $3 y$ & 0 & 1511 & 1826 & 3340 & 5 & 25 & 3 & 99 & 64 & $4,622,193$ & $2,557,539$ & 53 & 87 & Dominated \\
\hline $5 y$ & 0 & 1316 & 1080 & 2400 & 4 & 29 & 4 & 117 & 57 & $3,888,964$ & $1,824,309$ & 43 & 80 & Dominated \\
\hline $10 y$ & 0 & 1134 & 971 & 2110 & 4 & 31 & 5 & 121 & 54 & $3,656,827$ & $1,592,172$ & 41 & 78 & Dominated \\
\hline
\end{tabular}

COL, colonoscopy; CRC, colorectal cancer; LY, life-years; LYG, LY gained compared with no screening; Grey row indicates optimal screening strategy. ${ }^{a}$ Including deaths from complications of screening.

${ }^{b}$ Compared with no screening.

${ }^{c} \mathrm{CRC}$ cases and CRC death were not discounted. 
Supplementary Table 6. Outcomes With FIT Screening Strategies that Vary by the Ages to Begin and End Screening Among Transplant Cystic Fibrosis patients

Outcomes per 1,000 transplant cystic fibrosis individuals free of diagnosed cancer at age 30 years in 2017 (with organ transplant at age $30,3 \%$ discounted)

\begin{tabular}{|c|c|c|c|c|c|c|c|c|c|c|c|c|c|c|}
\hline & \multicolumn{2}{|c|}{ Screening tests } & \multirow[b]{2}{*}{$\begin{array}{c}\text { Surveillance } \\
\text { COLs }\end{array}$} & \multirow[b]{2}{*}{$\begin{array}{l}\text { Total } \\
\text { COLs }\end{array}$} & \multirow[b]{2}{*}{ Complications } & \multirow[b]{2}{*}{$\begin{array}{c}\text { CRC } \\
\text { cases }^{c}\end{array}$} & \multirow[b]{2}{*}{$\begin{array}{c}\text { CRC } \\
\text { death }^{a, c}\end{array}$} & \multirow[b]{2}{*}{$\begin{array}{l}\text { LY with } \\
\text { CRC }\end{array}$} & \multirow[b]{2}{*}{$\mathrm{LYG}^{b}$} & \multirow[b]{2}{*}{$\begin{array}{c}\text { Total costs } \\
(\$)\end{array}$} & \multirow[b]{2}{*}{$\begin{array}{l}\text { Net costs } \\
(\$)\end{array}$} & \multicolumn{2}{|c|}{ Reductions $^{b}(\%)$} & \multirow[b]{2}{*}{$\begin{array}{l}\text { Efficient } \\
\text { strategy }\end{array}$} \\
\hline & $\mathrm{FIT}$ & COLs & & & & & & & & & & $\begin{array}{c}\text { CRC } \\
\text { incidence }^{c}\end{array}$ & $\begin{array}{c}\text { CRC } \\
\text { mortality }^{c}\end{array}$ & \\
\hline No screening & 0 & 0 & 0 & 30 & 0 & 52 & 22 & 115 & 0 & $2,064,654$ & 0 & 0 & 0 & Dominated \\
\hline FIT 50-55 y & 327 & 0 & 88 & 189 & 1 & 54 & 15 & 153 & 13 & $2,467,521$ & 402,866 & -3 & 35 & Dominated \\
\hline FIT 50-60 y & 360 & 0 & 92 & 198 & 1 & 54 & 14 & 155 & 13 & $2,496,400$ & 431,746 & -4 & 36 & Dominated \\
\hline FIT 50-65 y & 364 & 0 & 92 & 199 & 1 & 54 & 14 & 156 & 13 & $2,501,575$ & 436,920 & -4 & 37 & Dominated \\
\hline FIT 50-70 y & 364 & 0 & 92 & 199 & 1 & 54 & 14 & 156 & 13 & $2,501,575$ & 436,920 & -4 & 37 & Dominated \\
\hline FIT 50-75 y & 364 & 0 & 92 & 199 & 1 & 54 & 14 & 156 & 13 & $2,501,575$ & 436,920 & -4 & 37 & Dominated \\
\hline FIT $45-55$ y & 813 & 0 & 181 & 322 & 1 & 48 & 11 & 165 & 25 & $2,517,648$ & 452,994 & 8 & 53 & Dominated \\
\hline FIT 45-60 y & 840 & 0 & 184 & 329 & 1 & 48 & 10 & 167 & 26 & $2,541,004$ & 476,350 & 7 & 54 & Dominated \\
\hline FIT 45-65 y & 843 & 0 & 184 & 329 & 1 & 49 & 10 & 167 & 26 & $2,545,324$ & 480,670 & 7 & 54 & Dominated \\
\hline FIT $45-70$ y & 843 & 0 & 184 & 329 & 1 & 49 & 10 & 167 & 26 & $2,545,324$ & 480,670 & 7 & 54 & Dominated \\
\hline FIT 45-75 y & 843 & 0 & 184 & 329 & 1 & 49 & 10 & 167 & 26 & $2,545,324$ & 480,670 & 7 & 54 & Dominated \\
\hline FIT 40-55 y & 1722 & 0 & 283 & 466 & 2 & 44 & 8 & 172 & 38 & $2,589,414$ & 524,759 & 15 & 65 & Dominated \\
\hline FIT 40-60 y & 1745 & 0 & 286 & 472 & 2 & 45 & 8 & 173 & 38 & $2,610,117$ & 545,463 & 14 & 66 & Dominated \\
\hline FIT 40-65 y & 1748 & 0 & 286 & 473 & 2 & 45 & 8 & 173 & 38 & $2,614,004$ & 549,350 & 14 & 66 & Dominated \\
\hline FIT $40-70$ y & 1748 & 0 & 286 & 473 & 2 & 45 & 8 & 173 & 38 & $2,614,004$ & 549,350 & 14 & 66 & Dominated \\
\hline FIT $40-75$ y & 1748 & 0 & 286 & 473 & 2 & 45 & 8 & 173 & 38 & $2,614,004$ & 549,350 & 14 & 66 & Dominated \\
\hline FIT $35-55$ y & 3419 & 0 & 377 & 620 & 2 & 42 & 6 & 175 & 48 & $2,755,648$ & 690,993 & 19 & 72 & Efficient \\
\hline FIT 35-60 y & 3440 & 0 & 380 & 625 & 2 & 42 & 6 & 177 & 48 & $2,774,500$ & 709,845 & 18 & 73 & Dominated \\
\hline FIT 35-65 y & 3443 & 0 & 380 & 626 & 2 & 43 & 6 & 177 & 48 & $2,778,104$ & 713,449 & 18 & 73 & Dominated \\
\hline FIT $35-70 y$ & 3443 & 0 & 380 & 626 & 2 & 43 & 6 & 177 & 48 & $2,778,104$ & 713,449 & 18 & 73 & Dominated \\
\hline FIT $35-75$ y & 3443 & 0 & 380 & 626 & 2 & 43 & 6 & 177 & 48 & $2,778,104$ & 713,449 & 18 & 73 & Dominated \\
\hline FIT 30-55 y & 6702 & 0 & 460 & 811 & 2 & 41 & 5 & 177 & 54 & $3,049,935$ & 985,281 & 21 & 76 & Efficient \\
\hline FIT 30-60 y & 6722 & 0 & 463 & 816 & 2 & 41 & 5 & 178 & 54 & $3,067,680$ & $1,003,026$ & 20 & 77 & Optimal \\
\hline FIT 30-65 y & 6725 & 0 & 463 & 816 & 2 & 42 & 5 & 178 & 54 & $3,071,052$ & $1,006,398$ & 20 & 77 & Dominated \\
\hline FIT $30-70$ y & 6725 & 0 & 463 & 816 & 2 & 42 & 5 & 178 & 54 & $3,071,052$ & $1,006,398$ & 20 & 77 & Dominated \\
\hline FIT $30-75$ y & 6725 & 0 & 463 & 816 & 2 & 42 & 5 & 178 & 54 & $3,071,052$ & $1,006,398$ & 20 & 77 & Dominated \\
\hline
\end{tabular}

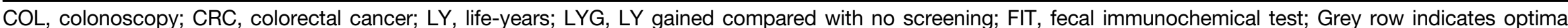
screening strategy.

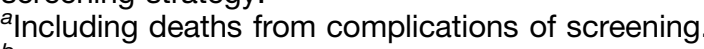

${ }^{b}$ Compared with no screening.

${ }^{c} \mathrm{CRC}$ cases and CRC death were not discounted. 
Supplementary Table 7.Efficient Colonoscopy Screening Strategies Among Non-transplant Cystic Fibrosis Patients (Assuming 5-fold and 10-fold Increased Rates of Cardiovascular Complications)

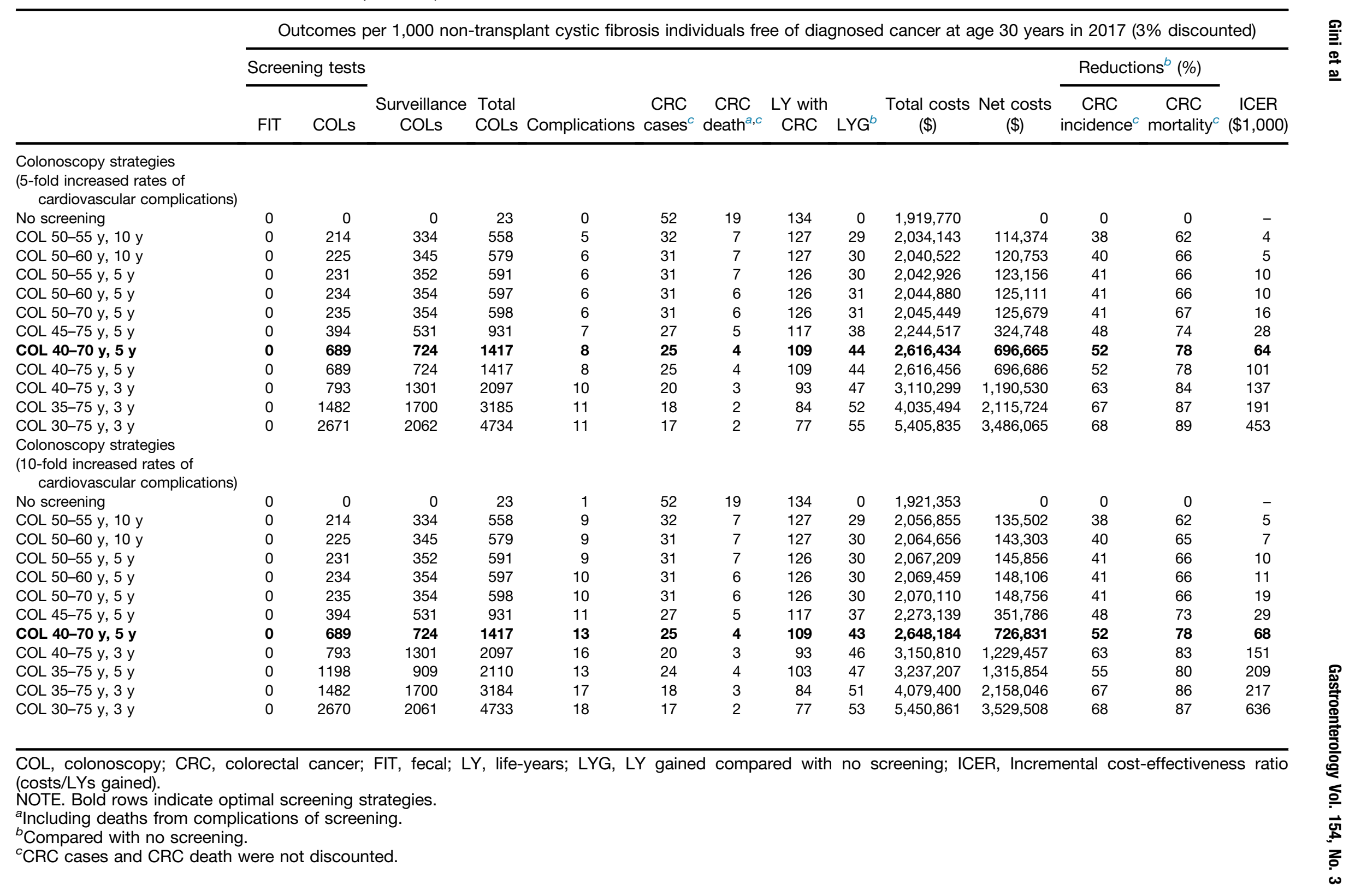


Supplementary Table 8. Efficient Colonoscopy Screening Strategies Among Transplant Cystic Fibrosis Patients (Assuming 5-fold and 10-fold Increased Rates of Cardiovascular Complications)

\begin{tabular}{|c|c|c|c|c|c|c|c|c|c|c|c|c|c|c|}
\hline & \multicolumn{14}{|c|}{$\begin{array}{l}\text { Outcomes per 1,000 transplant cystic fibrosis individuals free of diagnosed cancer at age } 30 \text { years in } 2017 \\
\text { (with organ transplant at age 30,3\% discounted) }\end{array}$} \\
\hline & \multicolumn{2}{|c|}{ Screening tests } & \multirow[b]{2}{*}{$\begin{array}{l}\text { Surveillance } \\
\text { COLs }\end{array}$} & \multirow[b]{2}{*}{$\begin{array}{l}\text { Total } \\
\text { COLs }\end{array}$} & \multirow[b]{2}{*}{ Complications } & \multirow[b]{2}{*}{$\begin{array}{l}\text { CRC } \\
\text { cases }^{c}\end{array}$} & \multirow[b]{2}{*}{$\begin{array}{c}\text { CRC } \\
\text { death }^{a, c}\end{array}$} & \multirow[b]{2}{*}{$\begin{array}{l}\text { LY with } \\
\text { CRC }\end{array}$} & \multirow[b]{2}{*}{$\mathrm{LYG}^{b}$} & \multirow[b]{2}{*}{$\begin{array}{l}\text { Total costs } \\
(\$)\end{array}$} & \multirow[b]{2}{*}{$\begin{array}{l}\text { Net costs } \\
(\$)\end{array}$} & \multicolumn{2}{|c|}{ Reductions $^{b}(\%)$} & \multirow[b]{2}{*}{$\begin{array}{c}\text { ICER } \\
(\$ 1,000)\end{array}$} \\
\hline & FIT & COLs & & & & & & & & & & $\begin{array}{c}\text { CRC } \\
\text { incidence }^{c}\end{array}$ & $\begin{array}{c}\text { CRC } \\
\text { mortality }^{c}\end{array}$ & \\
\hline \multicolumn{15}{|c|}{$\begin{array}{l}\text { Colonoscopy strategies } \\
\text { (5-fold increased rates of } \\
\text { cardiovascular complications) }\end{array}$} \\
\hline No screening & 0 & 0 & 0 & 30 & 0 & 52 & 22 & 115 & 0 & $2,065,435$ & 0 & 0 & 0 & - \\
\hline COL 45-55 y, 10 y & 0 & 199 & 342 & 553 & 4 & 39 & 10 & 139 & 28 & $2,452,010$ & 386,576 & 25 & 57 & 2 \\
\hline COL 45-55 y, 5 y & 0 & 200 & 343 & 554 & 4 & 39 & 9 & 139 & 28 & $2,452,589$ & 387,154 & 25 & 57 & 8 \\
\hline COL 40-55 y, 5 y & 0 & 324 & 591 & 923 & 6 & 34 & 7 & 129 & 42 & $2,618,834$ & 553,399 & 36 & 70 & 12 \\
\hline COL 35-55 y, 5 y & 0 & 607 & 838 & 1451 & 7 & 31 & 5 & 122 & 51 & $3,049,189$ & 983,754 & 41 & 77 & 46 \\
\hline COL 35-55 y, 3 y & 0 & 642 & 1265 & 1912 & 8 & 26 & 4 & 110 & 56 & $3,373,257$ & $1,307,822$ & 49 & 82 & 75 \\
\hline COL 30-55 y, 3 y & 0 & 1511 & 1825 & 3339 & 10 & 25 & 3 & 99 & 63 & $4,652,949$ & $2,587,514$ & 53 & 86 & 177 \\
\hline \multicolumn{15}{|c|}{$\begin{array}{l}\text { Colonoscopy strategies } \\
\text { (10-fold increased } \\
\text { rates of cardiovascular } \\
\text { complications) }\end{array}$} \\
\hline No screening & 0 & 0 & 0 & 30 & 0 & 52 & 22 & 115 & 0 & $2,066,410$ & 0 & 0 & 0 & - \\
\hline COL 45-55 y, 10 y & 0 & 199 & 341 & 553 & 7 & 39 & 10 & 139 & 28 & $2,469,059$ & 402,648 & 25 & 57 & 3 \\
\hline COL $45-55$ y, 5 y & 0 & 200 & 342 & 554 & 7 & 39 & 10 & 139 & 28 & $2,469,686$ & 403,276 & 25 & 57 & 10 \\
\hline COL $40-55$ y, 5 y & 0 & 324 & 591 & 923 & 9 & 34 & 7 & 129 & 42 & $2,641,176$ & 574,766 & 36 & 70 & 14 \\
\hline COL 35-55 y, 5 y & 0 & 607 & 838 & 1451 & 11 & 31 & 5 & 122 & 51 & $3,075,548$ & $1,009,138$ & 41 & 76 & 49 \\
\hline COL 35-55 y, 3 y & 0 & 642 & 1265 & 1911 & 13 & 26 & 4 & 110 & 55 & $3,406,590$ & $1,340,180$ & 49 & 81 & 85 \\
\hline COL $30-55$ y, 3 y & 0 & 1511 & 1825 & 3339 & 16 & 25 & 3 & 99 & 62 & $4,691,373$ & $2,624,962$ & 53 & 85 & 194 \\
\hline
\end{tabular}

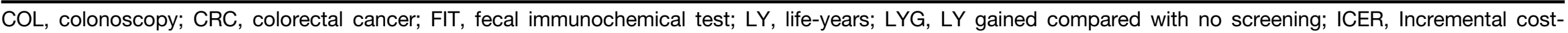
effectiveness ratio (costs/LYs gained).

NOTE. Bold rows indicate optimal screening strategies.

ancluding deaths from complications of screening.

${ }^{b}$ Compared with no screening.

${ }^{c} \mathrm{CRC}$ cases and $\mathrm{CRC}$ death were not discounted. 

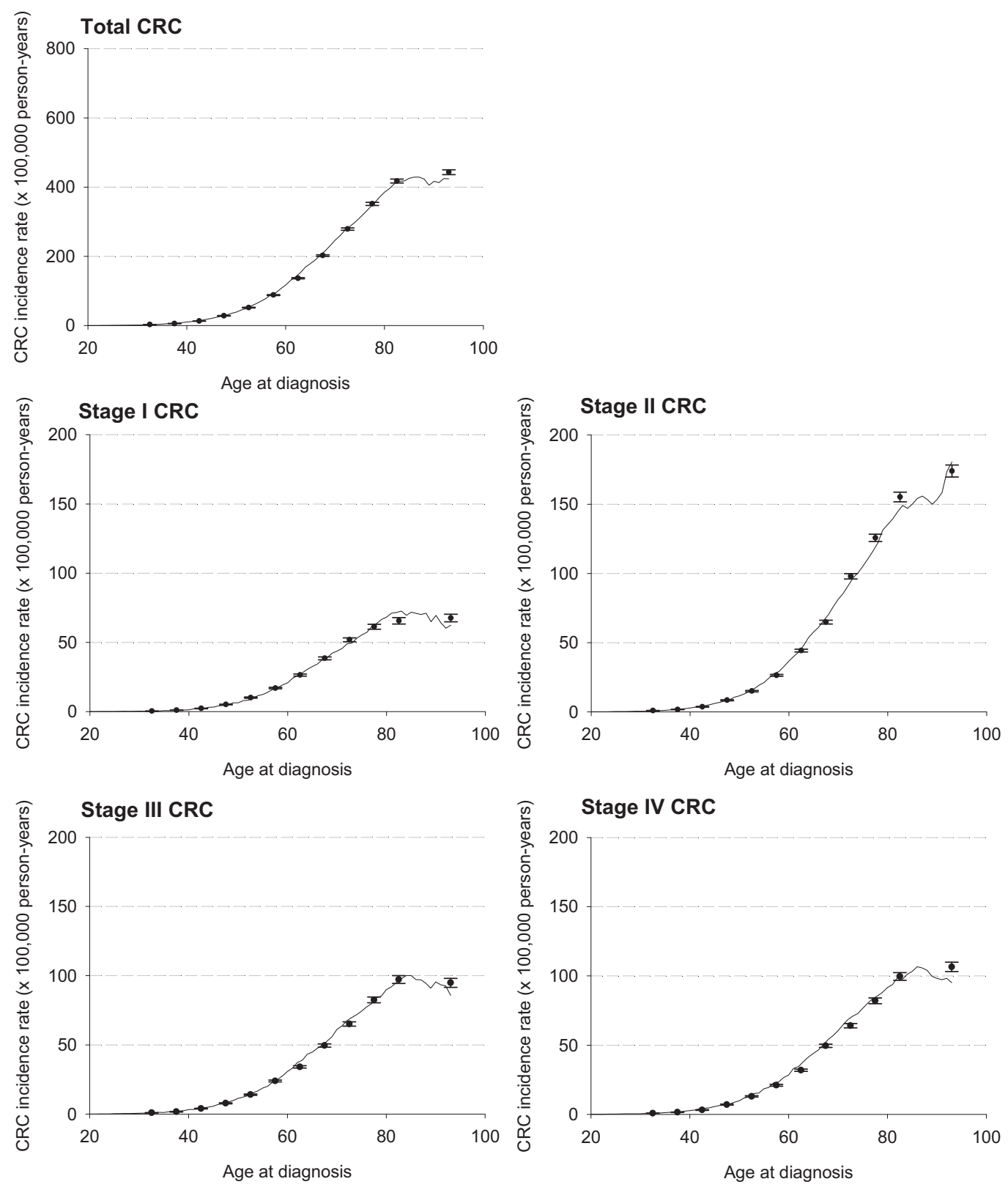

Simulated

- $\quad$ Seen in SEER 1975-1979

Bars indicate 95\% Cls. CRC = colorectal cancer; SEER = Surveillance, Epidemiology, and End Results.

Supplementary Figure 1. Colorectal cancer incidence seen before the introduction of screening vs incidence simulated by MISCAN-Colon model. 


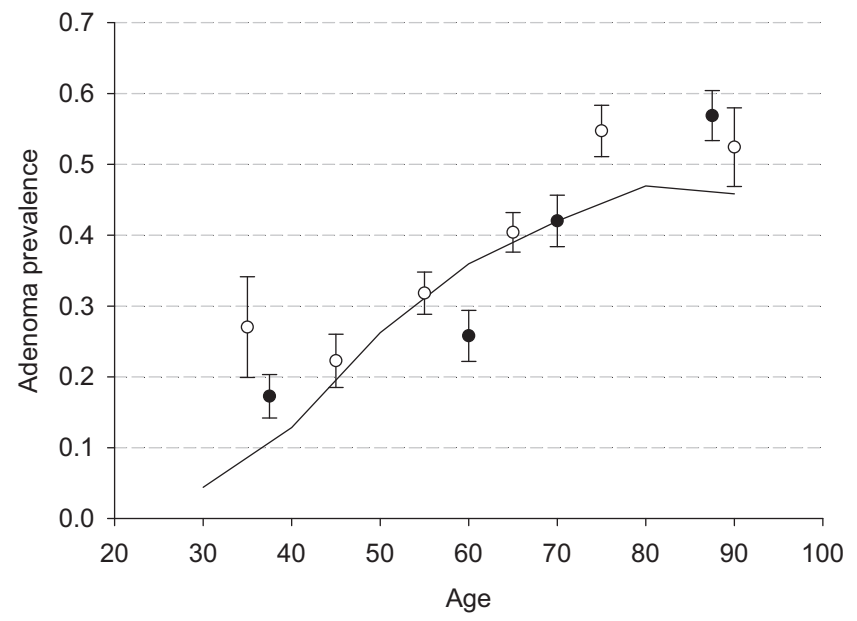

$$
\begin{array}{lll}
\text { - Simulated } & \text { Clarke et al. } 1985 &
\end{array}
$$

Supplementary Figure 2. Adenoma prevalence seen in selected autopsy studies vs prevalence simulated by MISCAN-Colon model. Observed results are shown only for the 2 largest studies on which the model has been calibrated. The model has additionally been calibrated to 8 other autopsy studies. Bars indicate 95\% Cls.
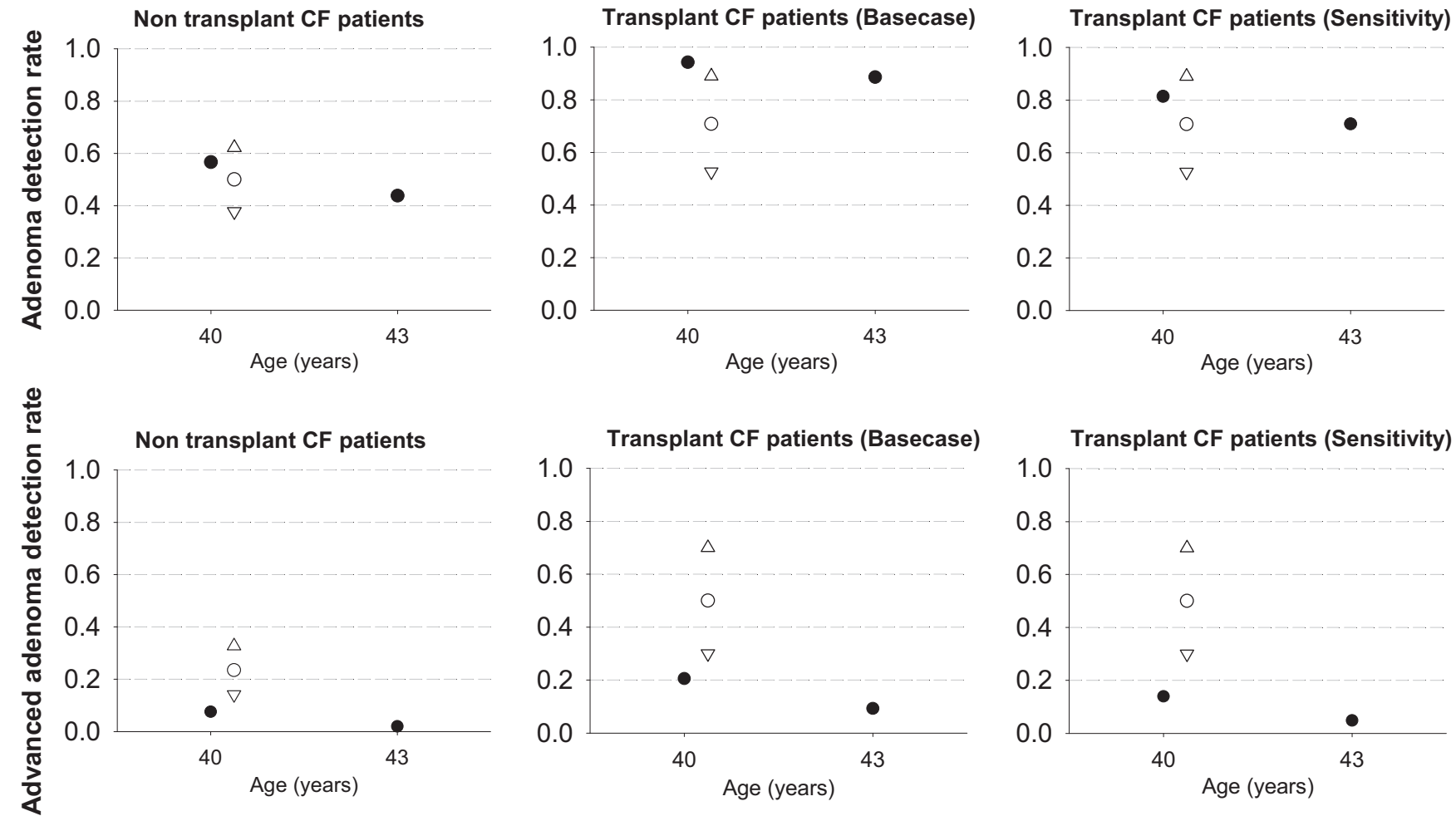

- Simulated in MISCAN-Colon

$\triangle 95 \% \mathrm{Cl}$ Upper bound

- As expected in Niccum DE et al. 2016

$\nabla \quad 95 \% \mathrm{Cl}$ Lower bound

Supplementary Figure 3. Adenoma and advanced adenoma detection rate simulated with Microsimulation Screening Analysis-Colon (MISCAN-Colon model) and observed in a colonoscopy observational study among cystic fibrosis patients. 
567.e15 Gin et al

Gastroenterology Vol. 154, No. 3

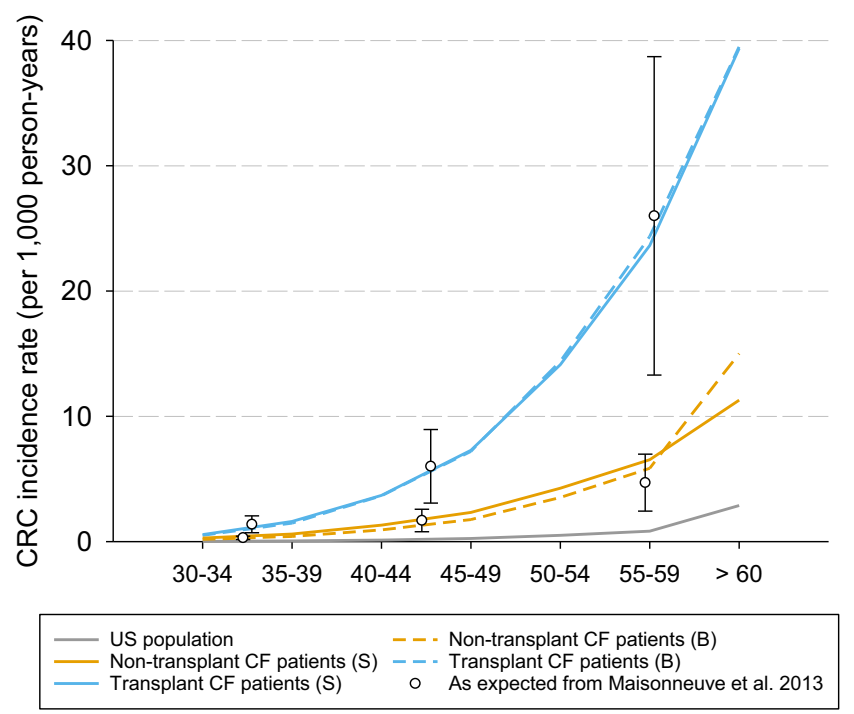

Supplementary Figure 4. CRC incidence expected in cystic fibrosis individuals according to Maisonneuve et al; 2013 and CRC incidence simulated in MISCAN-Colon model without screening in the US general population, non-transplant, and transplant CF patients assuming higher CRC risk through a combination of a more frequent adenoma onset and a faster adenoma progression (sensitivity analysis). Note: Bars indicate 95\% CIs; CRC, colorectal cancer; CF, cystic fibrosis; $\mathrm{B}$, base case analysis; $\mathrm{S}$, sensitivity analysis. 


\section{MISCAN-Colon Model Description (Model)}

\section{General Model Structure}

MISCAN-Colon is a stochastic microsimulation model for CRC that is useful in explaining and predicting trends in CRC incidence and mortality rates and to assess the effects and costs of primary prevention and screening for CRC. ${ }^{17}$

The model simulates the life history of each person at an individual level, rather than as proportions of a cohort. For that reason, the model allows the time dependence between future and past state transitions. However, in contrast to most traditional Markov models, MISCAN-Colon does not use yearly transition probabilities, rather it generates durations in states. This solution increases the model flexibility and computational performance. In addition, the model simulates sequences of events by drawing from distribution of probability or durations, rather than using fixed values. Hence, the results of the model are subject to random variation.

MISCAN-Colon consists of 3 modules: a demography module, natural history module, and screening module.

\section{The Demography Module}

The MISCAN-Colon model draws a date of birth and a date of no-CRC death for each individual simulated, using birth and life tables (representative of the population under consideration). The model restricts the maximum age a person can achieve to 100 years.

\section{The Natural History Module}

As each simulated person ages, 1 or more adenomas may develop (Supplementary Figure 5). These adenomas can be either progressive or non-progressive and both can grow in size from small $(<5 \mathrm{~mm})$ to medium $(6-9 \mathrm{~mm})$ and then to large $(>10 \mathrm{~mm})$. Only progressive adenomas can develop into preclinical cancer, which may progress through stages I to IV. However, during each stage, CRC may be diagnosed because of symptoms. After CRC clinical diagnosis, survival time is simulated using age-, stage-, and localization-specific survival estimates for clinically diagnosed CRC based on a study published by Rutter and colleagues. $^{19}$ For synchronous CRCs, survival is based on the most advance cancer. The date of death for CRC patients is the earliest simulated date of death (because of CRC or another cause).

The probability of adenoma onset differs among the individuals and depends on the person's age and risk index. For that reason, most persons do not develop adenomas and some others develop many. The distribution of adenoma over the colon and rectum was assumed equal to the distribution of cancer cases seen in SEER before the introduction of screening. ${ }^{38}$ The personal risk index and the age-specific onset of adenomas were calibrated to adenoma prevalence data obtained in several autopsy studies (Supplementary Figure 2). ${ }^{21-30,38}$ Furthermore, the age-specific probability of adenoma progressivity and the age- or localization-specific transition between preclinical and clinical cancer stages were calibrated to SEER data on age-, stage-, and localization-specific incidence of CRC in pre-screening years (ie, 1975-1979, Supplementary Figure 1). ${ }^{38}$ The average duration of the preclinical cancer stages were calibrated according to data obtained from randomized, controlled trials (RCTs) evaluating screening using guaiac fecal occult blood tests. ${ }^{10,11,14}$ The average duration between adenoma onset and progression into preclinical cancer (adenoma dwell time) was calibrated to the data on interval cancer seen in a sigmoidoscopy screening RCT. ${ }^{9}$ Furthermore, we assumed: an equal overall dwell time for adenoma developing into cancer from medium (30\% of all CRCs) and from large-size adenomas (70\% of all CRCs); exponential distribution for all duration in the adenoma and preclinical cancer phases; perfect correlation for the durations within adenoma and preclinical cancer (quicker growing from small adenoma and mediumsized adenoma, quicker developing into preclinical CRC); absence of correlation between durations in the adenoma phase and duration in the preclinical cancer phase.

\section{The Screening Module}

Screening will modify some of the simulated life histories. Some cancer cases will be prevented by the detection and removal of adenomas or by detection in an earlier stage (favorable survival). As seen in RCTs on guaiac fecal occult blood testing, the stage-specific survival of screen-detected CRC was more favorable compared with clinically detected CRC, even after the lead-time bias correction. ${ }^{12}$ Hence, we assigned those screen-detected cancer cases - that without screening would have been clinically detected in the same stage - a survival corresponding to a cancer that is 1 stage less progressive. The only exceptions were screen-detected stage IV cancer cases: we assigned the survival of a clinically diagnosed stage IV cancer. Furthermore, together with the positive effects of screening, we also modelled overdiagnosis, overtreatment, and colonoscopy-related complications. $^{36}$

\section{Integrating Modules}

For each person simulated, a date of birth and a date of no-CRC death (a lifetime history without adenoma or CRC) are generated from the demography module. In patient $\mathrm{A}$ in Supplementary Figure 6, the natural history module generates an adenoma. This adenoma progresses into preclinical cancer (diagnosed as stage II CRC because of symptoms) and results in CRC death before non-CRC death would have occurred. However, in the screening module, a screening examination is introduced: the adenoma is detected, removed, and the CRC death prevented. The positive effect of the screening intervention is indicated by the green arrow and represents the increased LYG for this patient because of screening. Another example is patient B, who develops an adenoma that would never have been diagnosed in a no-screening scenario. However, during the screening examination, CRC is screen-detected in stage I and - for this patient - screening results in overdiagnosis and overtreatment of CRC (no LYG, but only additional LYs with CRC care). 


\section{Results for US General Population (Included in this Study)}

According to the MISCAN-Colon model, up to $73 \%$ of CRC deaths may be avoided by introducing CRC screening in the US general population (Table 1). While this result may appear elevated considering the findings of several RCTs, ${ }^{9,15-17}$ it is in accordance with assumptions made in our analysis. We investigated the impact of screening in the entire colorectum with $100 \%$ adherence to screening (in each screening round) and surveillance tests. The
RCTs mainly investigated the effect of screening on the left colon (once-only flexible sigmoidoscopy), reporting a $22 \%-31 \%$ reduction in CRC mortality with a compliance ranging from $58 \%$ to $71 \%$. $^{9,15,17}$ Schoen et al reported a $50 \%$ reduction in distal CRC mortality in those invited to flexible sigmoidoscopy $(54 \%$ of adherence in those invited to repeat screening every 5 or 3 years). ${ }^{16}$ Furthermore, the MISCAN-Colon model is calibrated and validated against data from the UK flexible sigmoidoscopy screening trial. ${ }^{34}$

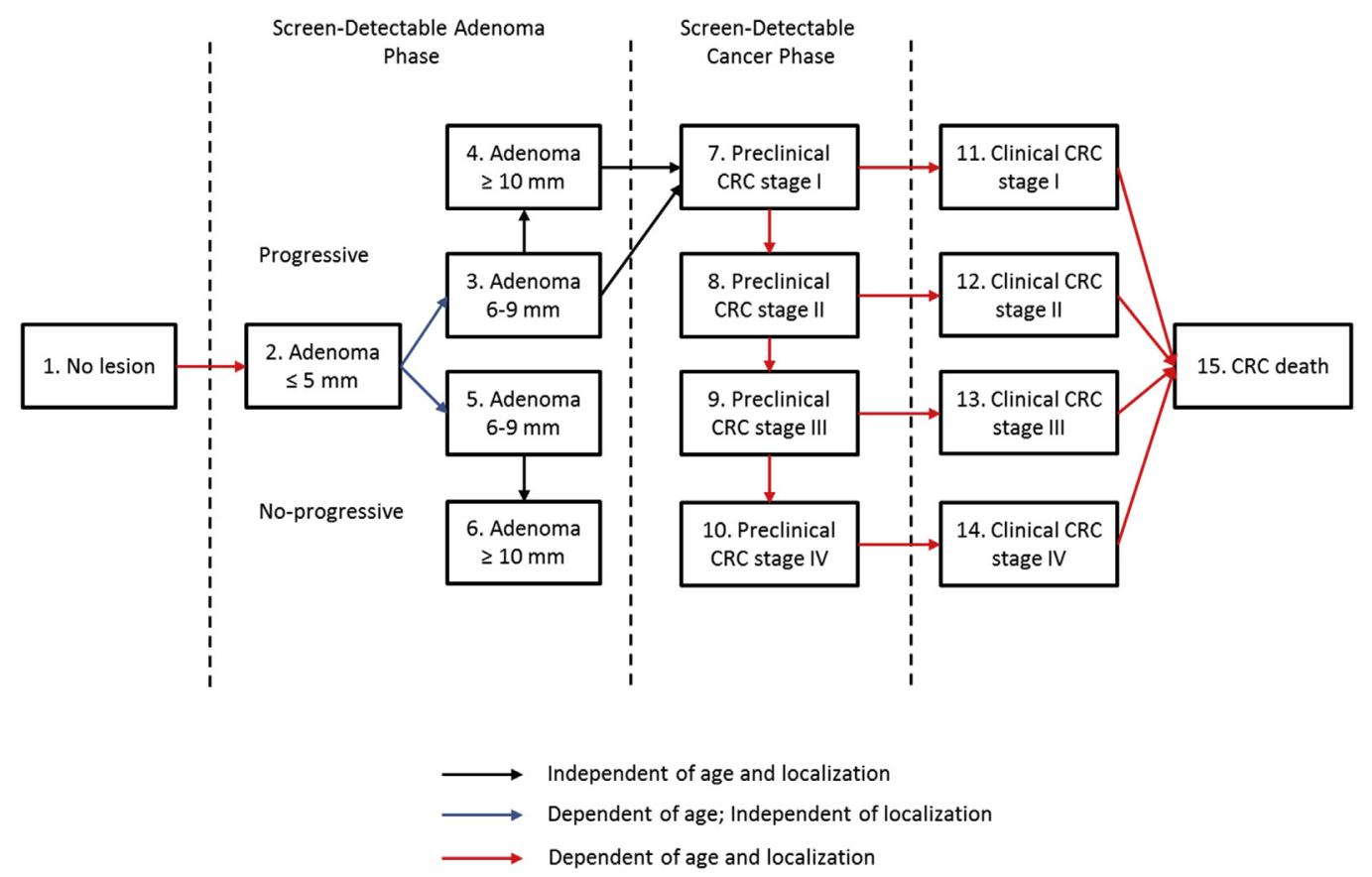

Supplementary Figure 5. The general model structure of the MISCAN-Colon model. 
Patients A: Benefitting from screening

Demographic module

Life history 1

(without adenomas/CRC)

Natural history module

Life history 2

(develops CRC)

Screening module

Life history 3

(has screening)

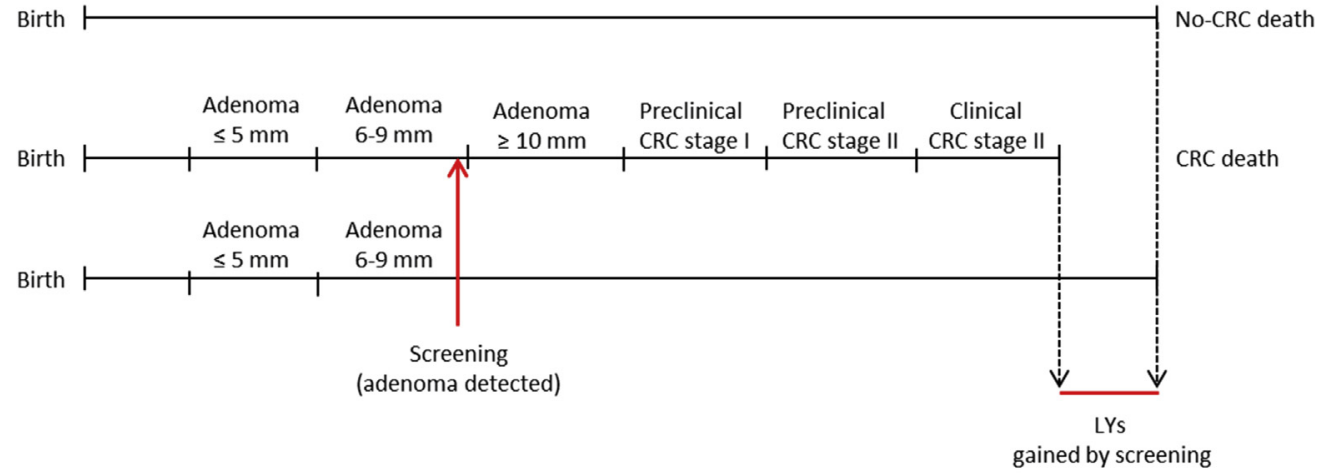

Patients B: Overdiagnosing

Demographic module

Life history 1

(without adenomas/CRC)

Birth

Natural history module

Life history 2

(develops CRC)

Screening module

Life history 3

(has screening)

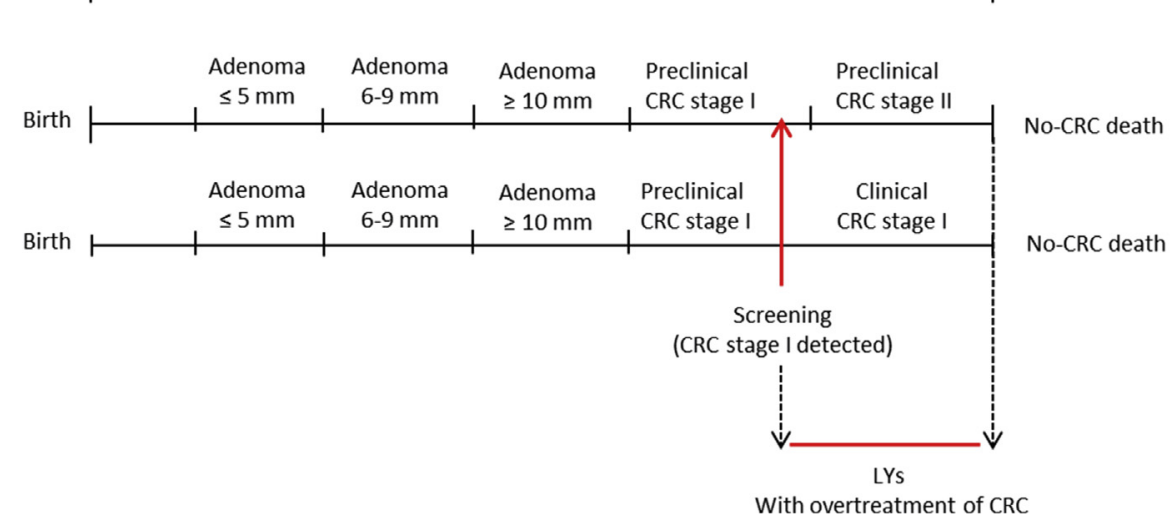

Supplementary Figure 6. Integrating modules with 2 examples. 